\title{
Important Plant Areas: revised selection criteria for a global approach to plant conservation
}

\author{
Iain Darbyshire ${ }^{1}$ Seona Anderson ${ }^{2}$ Anna Asatryan ${ }^{3}$ Andrew Byfield ${ }^{2}$. \\ Martin Cheek $^{1}$ - Colin Clubbe ${ }^{1} \cdot$ Zeineb Ghrabi $^{4} \cdot$ Timothy Harris $^{5}$. \\ Charlie D. Heatubun ${ }^{6} \cdot$ James Kalema $^{7}$ - Sékou Magassouba ${ }^{8}$. \\ Ben McCarthy ${ }^{2}$ - William Milliken ${ }^{1}$ - Bertrand de Montmollin' • \\ Eimear Nic Lughadha ${ }^{1}$ Jean-Michel Onana ${ }^{10}$ - Doumbouya Saïdou ${ }^{11}$. \\ Anca Sârbu $^{12}$ - Krishna Shrestha ${ }^{13}$ - Elizabeth A. Radford ${ }^{14}$ \\ Received: 23 September 2016/Revised: 4 January 2017/Accepted: 10 February 2017 / \\ Published online: 29 March 2017 \\ (C) The Author(s) 2017. This article is an open access publication
}

\begin{abstract}
Despite the severe threats to plant habitats and high levels of extinction risk for plant species in many parts of the world, plant conservation priorities are often poorly represented in national and global frameworks because of a lack of data in an accessible and consistent format to inform conservation decision making. The Important Plant Areas (IPAs) criteria system offers a pragmatic yet scientifically rigorous means of delivering these datasets, enabling informed national- or regional-scale conservation prioritisation, and contributing significantly towards global prioritisation systems including the International Union for Conservation of Nature Key Biodiversity Areas (KBAs) Standard. In this paper, we review the IPA rationale and progress on IPA identification to date, including the perceived limitations of the process and how these may be overcome. We then present a revised set of criteria for use globally, developed through the combined experiences of IPA
\end{abstract}

Communicated by Daniel Sanchez Mata.

This article belongs to the Topical Collection: Biodiversity protection and reserves.

Iain Darbyshire

i.darbyshire@kew.org

1 Royal Botanic Gardens, Kew, Richmond, Surrey TW9 3AB, UK

2 Plantlife International, Brewery House, 36 Milford Street, Salisbury SP1 2AP, UK

3 Institute of Botany of the National Academy of Sciences of Armenia, 1 Acharyan Street, 0040 Yerevan, Armenia

4 Institut National Agronomique de Tunisie (INAT), 43 Avenue Charles Nicolle, 1082 Tunis, Tunisia

5 University College London, Gower Street, London WC1E 6BT, UK

6 Faculty of Forestry and Center for Biodiversity Research, Universitas Papua, J1. Gunung Salju, Amban, Manokwari, Papua Barat 98314, Indonesia

7 Makerere University Herbarium, College of Natural Sciences, Makerere University, P.O. Box 7062, Kampala, Uganda 
identification over the past decade and a half and through a recent global consultation process. An overview of how the revised IPA criteria can work alongside the newly published KBA Standard is also provided. IPA criteria are based around a sound, scientific, global framework which acknowledges the practical problems of gathering plant and habitat data in many regions of the world, and recognises the role of peer reviewed expert opinion in the selection process. National and sub-national engagement in IPA identification is essential, providing a primary route towards long term conservation of key sites for plant diversity. The IPA criteria can be applied to the conservation of all organism groups within the plant and fungal kingdoms.

Keywords Botanical richness - Complementarity · GSPC · KBA · Prioritisation · Threatened habitat $\cdot$ Threatened species · Useful plants

\section{Introduction}

Current estimates suggest one in five of the world's plant species is threatened with extinction globally (International Union for Conservation of Nature, IUCN Sampled Red List Index for Plants 2012; Sharrock et al. 2014; Brummitt et al. 2015; Bachman et al. 2016). Despite commitments by the international community to halt biodiversity decline, for example through implementing the Convention on Biodiversity (CBD 1992) and the associated Aichi Biodiversity Targets (CBD 2012a), conservation efforts targeting plant diversity are often hampered by lack of suitable data for prioritising conservation action. Information on the rarest and most threatened plants and habitats, and where they occur, is often diffuse and difficult to access or is outdated. As a result, plants are typically not well represented in either global or national conservation planning schemes (Corlett 2016), where faunal groups are commonly used to define key localities and their management priorities, on the basis of more accessible data from initiatives such as the Important Bird and Biodiversity Areas (IBAs; Birdlife International 2014).

Whilst initial studies indicate that the congruence between IBAs and important sites for other vertebrate taxa is high (Brooks et al. 2001; Eken et al. 2004), wider cross-taxon congruence can vary tremendously (e.g., Lund and Rahbek 2002; Kati et al. 2004; Heino 2010; Sabatini et al. 2016) and evidence suggests that the congruence between important sites for plants and those for faunal groups may be considerably lower. For example, an

8 Herbier National de Guinée, Université Gamal Abdel de Conakry, BP 680, Conakry, Guinea

9 IUCN/SSC Mediterranean Plant Specialist Group (MPSG), Rue de la Serre 5, 2000 Neuchâtel, Switzerland

10 Département de Biologie et Physiologie Végétales, Faculté des Sciences, Université de Yaoundé I, Yaoundé, Cameroon

11 Ministre de l'Environnement des Eaux et Forêts, Republic de Guinée, BP 761, Conakry, Guinea

12 Facultatea de Biologie, Universitatea din Bucureşti, Srt. Intrerea Portocalelor 1-3, Sector 6, 060101 Bucharest, Romania

13 Ethnobotanical Society of Nepal (ESON), Kathmandu, Nepal

14 Royal Society for the Protection of Birds (RSPB), International Directorate, The Lodge, Sandy, Bedfordshire SG19 2DL, UK 
analysis of Important Plant Areas (IPAs), IBAs and Prime Butterfly Areas (PBAs) in Bulgaria, Croatia, Macedonia and Montenegro found a 52\% overlap or partial overlap between IBAs and IPAs and $65 \%$ between PBAs and IPAs across the four countries (Radford and Odé 2009, Table 9). Similarly in Turkey, a review in 2010 of the 122 IPAs, 97 IBAs and 17 Sea Turtle breeding areas in Turkey found that only c. 50 sites shared two of these three designations (Byfield et al. 2010), although this overlap has increased as further sites have been added to the IBA network in Turkey and the overlap between IPAs and IBAs now stand at 76 sites. Furthermore, for sites that are identified as important on faunal grounds, plants are rarely considered in the management strategies for these sites even if they are also of high botanical importance. Therefore, there is a clear and urgent need to identify site-based plant conservation priorities on a systematic, global basis and to make these data available and easily accessible to national, regional and international policy makers for maximum impact on environmental decision-making.

The IPAs programme, developed in the early 2000s by Plantlife International, offers a practical yet scientifically robust means of achieving this aim. The concept of IPAs was inspired by the original Important Bird Area concept developed by Birdlife International (e.g., Grimmett and Jones 1989; Heath and Evans 2000), which has been a successful tool for promoting targeted bird and wider biodiversity conservation globally (Butchart et al. 2012). IPAs are defined as the most important places in the world for wild plant and fungal diversity that can be protected and managed as specific sites (Plantlife International 2004). IPAs anywhere in the world are identified on the basis of three consistent criteria: the presence of threatened species, exceptional botanical richness and threatened habitats (Anderson 2002; Plantlife International 2004). The identification process is led by national IPA constituencies who use the best available national, regional and global data in a clear and transparent manner to select and publish national IPA networks. IPAs are not legal site designations; rather they are a means of identifying and communicating the importance of a national or regional network of key sites for wild plants and habitats that together can help to conserve global plant diversity. They can provide an assessment of the importance of existing protected area mechanisms for plant conservation, highlight gaps in the national protected areas network or form the basis for community-based and citizen science-led conservation and sustainable management initiatives. Further, IPAs can be an important tool in the avoidance stage of the mitigation hierarchy in industry and development (see Saenz et al. 2013 for an example of mitigation strategies). Through providing clear evidence of the biodiversity value of a site, IPA networks can be an important tool for environmental and social impact assessments at the planning stage of major development projects.

IPAs are directly aligned to Target 5 of the CBD Global Strategy for Plant Conservation (GSPC): "At least $75 \%$ of the most important areas for plant diversity of each ecological region protected with effective management in place for conserving plants and their genetic diversity" (CBD 2012b; Sharrock 2012). Indeed, the IPA initiative was a driving force behind this target when the GSPC was formally adopted by the CBD (2002). All of the 196 parties who have ratified the CBD are committed to meeting this as one of 16 targets for global plant conservation by the year 2020. A national programme to identify areas most important for plant diversity (e.g., IPAs), coupled with a post-identification programme of site prioritisation, protection and monitoring is essential for delivering national commitments to GSPC Target 5.

The IPA criteria are aligned with internationally recognised measures of threat to biodiversity, notably the IUCN Red List of Threatened Species (2012) and potentially also the IUCN Red List of Ecosystems (Bland et al. 2015). However, we recognise that 
currently many plant and fungi species have undergone no formal assessment of their threat status - to date only c. 5\% of all plant species have been assessed applying IUCN criteria (Bachman et al. 2016) - and that there is no current global list of threatened habitats and little prospect of such a list being finalised in the imminent future. Therefore we advocate the principle of national, peer-reviewed, published threat lists as part of the IPA identification process, alongside regional consultation across national boundaries, as key steps towards formal threat assessment.

\section{A national approach to global conservation priorities}

One of the central tenets of the IPA system is that national decision making from the outset of the identification process is key to encouraging participation, data accumulation, ownership of the results, and the long term conservation of key sites for plants. Much of the plant and habitat data that exist are held at the national level and many of the conservation frameworks that affect priority sites, such as environmental and planning legislation, protected area networks and land ownership systems, operate at the national level. IPAs represent a pragmatic and proven approach to national plant conservation that can complement other initiatives such as National Biodiversity Strategies and Protected Area management.

The IPA programme has a bottom-up approach which encourages sub-national and national cooperation, together with regional consultation for sharing of data and expertise, and which does not rely on the completion of global species and habitat assessments before site identification can begin. The important role of peer-reviewed expert opinion at the national and regional level is recognised in the IPA identification process.

As part of national IPA identification projects, the data gathered on threatened species and habitats has great potential to improve the current low levels of global conservation assessments for plants and vegetation. Where global population and habitat data do exist, they will be recorded in IPA site identification documentation and in the IPA database (Plantlife 2010a), thus generating essential data for other global assessments of biodiversity including the IUCN Key Biodiversity Areas (KBAs) programme (2016, see Section 3) and systematic conservation planning (SCP) schemes (Margules and Pressey 2000; Smith et al. 2006). Nationally led identification work based on globally agreed criteria can inform and be informed by global initiatives but it cannot be bypassed if the aim is to increase local awareness and conservation action on the ground.

The future of many of our rarest and most threatened plant species and habitats will only be safeguarded through protection and/or sustainable management of a network of the most important sites. For those rare and threatened species and habitats that extend across political borders, protection of sites across the full geographic range offers the greatest hope for their long-term conservation, as it will ensure that multiple parties are invested in their survival as well as encouraging regional conservation efforts and cooperation. This is particularly important in cases where standards and expertise in biodiversity conservation differ significantly between neighbouring countries. A species may have $95 \%$ of its global population in one country and only $5 \%$ in a second, but if the conservation expertise and opportunities in the latter country are considerably higher than the former, then protection of, and research on, that $5 \%$ of the global population may be critical to its long-term survival. Furthermore, evidence suggests that edge-of-range populations and their associated genetic traits may be important in terms of resilience of species to climate change and associated environmental flux (Hampe and Petit 2005; Leppig and White 2006; Mátyás et al. 2009; Bjedov et al. 2015; Rehm et al. 2015). Hence, small national edge-of-range 
populations of range-restricted species may be of global conservation importance. A purely global approach to conservation prioritisation may omit such important considerations.

\section{Progress to date on IPA identification and post-identification programmes}

Great headway has been made in the identification of IPA sites in large parts of Europe, North Africa and the Middle East (see, for example, Anderson et al. 2005; Özhatay 2006; Radford and Odé 2009; Byfield et al. 2010; Melovski et al. 2010, 2012; Plantlife 2010a; Blasi et al. 2011; Radford et al. 2011; Asatryan and Fayvush 2013), with 1994 IPAs in 27 countries identified and documented across this region to date (figure updated from Plantlife International 2010). In many cases, the resultant IPA networks have been integrated into national conservation planning and monitoring schemes (see Plantlife 2010b; Plantlife International 2010). For example, in Belarus all IPAs are now protected by law (Maslovsky pers. comm.), and in Romania IPAs have led to the recognition and protection of new critical habitats (Sârbu et al. 2007), whilst in Croatia many IPAs were included in the expanded protected area network under the Natura 2000 scheme as part of their accession to the European Union in 2013. In the UK, IPAs form the basis for Plantlife's UK conservation programme, specifically focussed on conserving rare and threatened plant species and habitats, while in the East and South Mediterranean Plantlife is working with the IUCN Centre for Mediterranean Cooperation, the IUCN/SSC/Mediterranean Plant Specialist Group and national partners to develop species monitoring plans and community action for IPA sites (IUCN 2014). IPAs have also played a role in preventing destruction of key sites. For example, the IPA status of Mavrovo National Park in Macedonia was referenced within the Bern Convention expert report, a significant piece of evidence in the successful campaign to halt plans to construct two hydro-electric dams, Lukovo Pole and Boskov Most, within areas of the park (Galland 2015).

IPA identification work in Europe and the Mediterranean region has highlighted variable, and sometimes low levels of co-incidence between IPAs and statutory site protection, and that even those IPAs falling within Protected Areas are rarely managed for their plants. As of 2010, one in four IPAs in Europe had no legal protection and many are threatened (Plantlife 2010b). In Turkey, of the 122 IPAs identified in the original assessments, 94\% were exposed to at least one threat factor and over $75 \%$ were threatened by two or more factors (Byfield et al. 2010). It is clear that if countries are to meet GSPC and Aichi Targets then the momentum gained through IPA identification must be carried forward into postidentification protection and monitoring programmes within the national IPA network. Whilst legal protection may be a favourable option for many IPAs, civil society-led initiatives will also be critical in securing the long-term survival of IPA sites (Plantlife 2013). For example, in Turkey, Doğal Hayatı Koruma Derneği (the Society for the Protection of Nature) and the Rubicon Foundation (Netherlands) have helped to establish an IPA volunteer network-IPANET - in the first instance focussing on nine critical IPAs where volunteers have been trained in natural resource management issues including monitoring of rare species and habitats, promoting sustainable use and management, and taking action at IPAs that need protection (Radford and Odé 2009; ÖBANET 2015; Anderson et al. 2016).

Beyond Europe and the Mediterranean region, a number of IPA initiatives have been launched or piloted and to date 69 countries have made at least an initial assessment of their IPAs (Plantlife 2010b; Anderson et al. 2016). For example, a series of IPA workshops was held for the southern Africa region in 2004 as part of the Southern African Botanical Diversity Network (SABONET) programme (Smith 2005), with documentation of 39 
proposed IPAs in Namibia (Hofmeyr 2004). In the Himalaya region, a regional workshop was held in 2006 on the identification and conservation of IPAs for Himalayan medicinal plants, organized by Plantlife International and the Ethnobotanical Society of Nepal, and attended by experts from Bhutan, China, India, Nepal and Pakistan (Hamilton and Radford 2007). That study resulted in the identification of 53 broadly defined IPAs for medicinal plants, with 268 more specific local sites identified. In Arabia, an IPA programme was launched in 2010, adopting a modified set of criteria to that used in Europe (Al-Abbasi et al. 2010) and applied to four Saudi Arabian sites to date (e.g., Llewellyn et al. 2011). In the UK Overseas Territories, 17 IPAs have been identified and documented in the Falkland Islands (Upson 2012; Upson et al. 2016), which have been incorporated into the revised Falkland Islands Government Biodiversity Strategy, and the IPA process has been initiated in several Caribbean islands (Jones 2008; Williams 2009; Linsky 2014). New countries continue to adopt and apply the IPA criteria; for example, a first assessment of 31 IPAs in Kazakhstan has recently been published (Dimeyeva and Vesselova 2015).

However, in large of areas of the tropics in particular, information on IPAs, and on the species and habitats that underpin these important sites, is often lacking or incomplete (Fig. 1). Much of the world's plant diversity is concentrated in these tropical regions-two thirds of all angiosperm species according to Pimm and Joppa (2015)—where existing protected area networks and national legislation frequently fail to protect key plant species and their habitats. The need for accelerated IPA identification and protection in the tropics, and an associated drive to mobilise existing and new plant data, is therefore particularly urgent. With this in mind, the Royal Botanic Gardens, Kew (henceforth Kew), in collaboration with its in-country partners and with Plantlife International, launched the Tropical IPAs (TIPAs) programme in 2015 (RBG Kew 2016; Anderson et al. 2016). In the first phase of this work, Kew has committed to assisting in-country plant scientists and

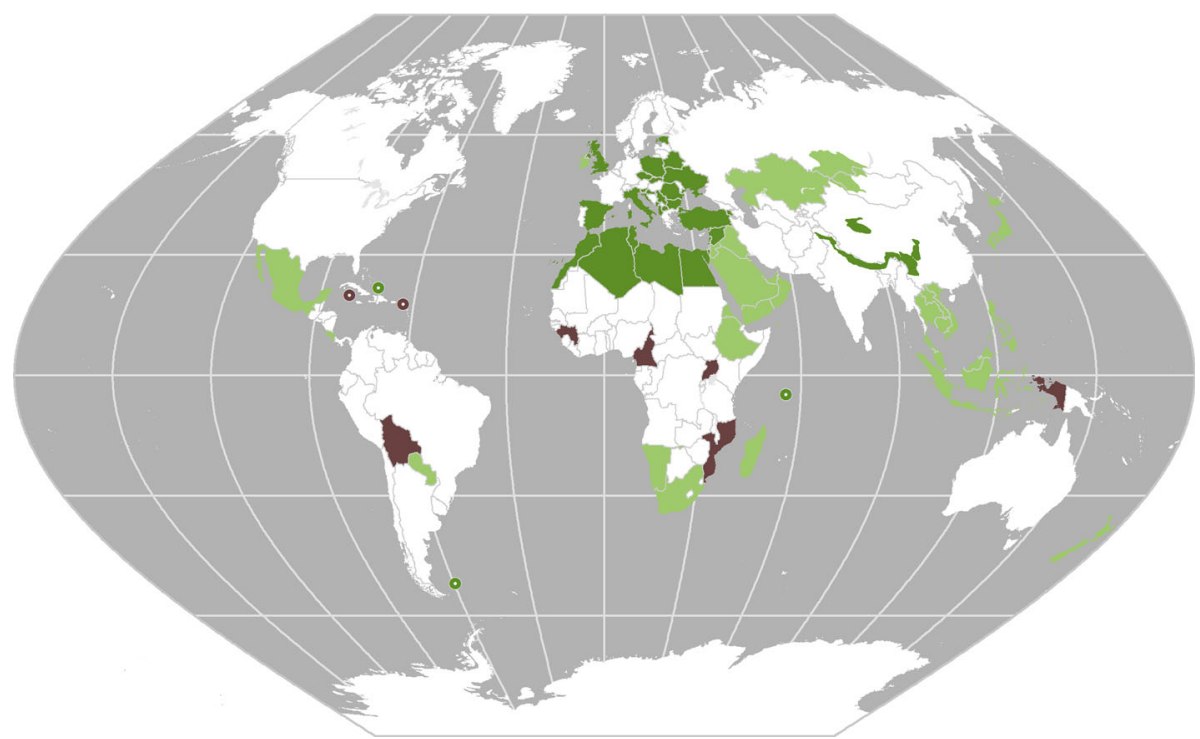

Fig. 1 Countries and regions of the world with an IPA programme. Dark green IPAs identified and documented, pale green IPA programme initiated but sites not fully documented, dark brown tropical IPAs programme (RBG Kew 2016). Modified from Anderson et al. (2016), with permission from the Trustees of the Royal Botanic Gardens, Kew. (Color figure online) 
conservationists in the identification of IPAs in seven countries/regions by 2020: Bolivia, Cameroon, Guinée, Indonesian New Guinea (Papua and West Papua Provinces of Indonesia), Mozambique, Uganda and UK Overseas Territories in the Caribbean. We hope that this will stimulate a greater impetus for the identification of IPAs globally.

\section{Potential limitations of IPAs}

As with all such initiatives, progress on IPA identification is limited primarily by the availability of raw data on the distribution, rarity and threat status of plant species and their habitats, and by the severely limited resources to harness existing data and infill gaps in our knowledge. It is this resource limitation that is the primary reason for limited or stalled progress in IPA identification in some of countries highlighted in pale green on Fig. 1. However, the global community has agreed, through the GSPC, that mobilising such data and applying it to specific conservation targets is a priority, and the botanical community therefore needs to rise to this challenge. A combined plant species conservation assessment and IPA programme, whilst requiring a large commitment in terms of funding and labour resources, offers a genuine opportunity to make botanical data more accessible to a wide range of audiences and to promote effective conservation prioritisation and implementation.

Of course, the IPA methodology may not be considered the optimal approach in all circumstances. South Africa is a case in point. Under the SABONET programme, the participating countries from southern Africa considered the adoption of the IPA criteria-led approach as a means of addressing Target 5 of the GSPC, although it was conceded that the IPA method may not be equally suitable for all of the SABONET countries (Smith and Smith 2004). A modified set of criteria suitable for regional use was therefore developed and a series of country-specific workshops were held, including in South Africa (Smith 2005). However, it was subsequently felt that insufficient fine-scale plant distribution data were available at the time to allow practical implementation of the IPA process (von Staden and Lotter 2015). A decade later, whilst South Africa now has an enviably rich botanical dataset including the first complete national red list of plant species for a megadiverse country (SANBI 2015), it has instead adopted a SCP approach to identifying sites of importance for preserving biodiversity, including plants. Von Staden and Lotter (2015) note that the criteria-based approach is now out of step with the well-established SCP approach in South Africa and, further, that preliminary testing shows the criteria to be too "land-hungry" within a megadiverse country context. They focussed on the criteria of KBAs (IUCN 2016), but the comments could equally be levelled at IPAs.

There is certainly a valid concern that threshold-based criteria can be too inclusive depending on the thresholds set, and that thresholds suitable for one region or country may not be so for another. However, at least in the case of IPAs, this can be overcome. The IPA approach advocates national decision-making within a criteria framework. Therefore, the criteria alone do not define the designation of IPAs; there is a two-stage process in which the national IPA constituency selects the most important sites from amongst those that meet the criteria (rather than selecting every site that meets at least one criterion). This decision should be made in an informed and transparent manner, taking into account the full range of factors that dictate the importance of a network of sites. Critically, this should include site complementarity, as well as site viability, how many criteria each site meets, and how many qualifying species and/or habitats it contains. Further, the thresholds presented in the criteria are advisory rather than absolute. As IPAs are assessed on a national or regional scale, the relevant IPA constituency can choose by consensus to modify the 
criteria thresholds in order to make them optimal for the region or country in question, so long as this is justified and is applied consistently.

A further perceived weakness of the criteria-based approach is that it may not give due consideration to site complementarity. That said, the IPA approach encourages the assessment of a full network of complementary sites at the national and regional level as a means of prioritising site-based conservation rather than the piecemeal selection of sites. Marignani and Blasi (2012) compared criteria-based and complementarity approaches for identifying IPAs in Italy, analysing the coverage of beta-diversity and land cover within the resulting site networks. The criteria-based approach unexpectedly proved to be more effective in selecting beta-diversity. In terms of land cover composition, the criteria-based approach selected natural and semi-natural areas whilst the complementarity approach selected primarily agricultural areas, suggesting that the latter approach can help to pinpoint those areas in which conservation actions are most urgently needed. Thus, they concluded that an integration of the two approaches in a SCP scheme may be optimal to help refine the IPA network identified through the criteria-based approach.

\section{Consultation on revised IPA selection criteria}

Whilst efforts were made from the outset to ensure that the IPA criteria could be applicable globally, the original criteria (Anderson 2002) were designed primarily with Europe in mind and so incorporated European Union legislation into the criteria thresholds, notably the Bern Convention (Council of Europe 1979) and resultant EU Habitats Directive (1992). Furthermore, relative to other regions of the world, most European countries are data-rich in terms of information on rare and threatened plant species and habitats, and this was reflected in the data requirements for some parts of the IPA criteria. As IPAs have been assessed more widely, often in relatively data-poor regions and those with different conservation legislation, some modifications to the criteria themselves, or the way in which the criteria should be applied, have been proposed and used in the assessment of IPAs (see, for example, Smith 2005; Al-Abbasi et al. 2010; Radford et al. 2011). However, the formal IPA criteria have remained unaltered until now.

A wealth of experience has been gained in best practice in IPA identification, documentation and post-identification work through the IPA partnerships in Europe, the Mediterranean region and beyond. With this in mind, and with the launch of the TIPAs programme, it is an appropriate time to combine the collective knowledge and experiences of the past decade to fine-tune the criteria for a new phase of IPA identification in the tropics and beyond. A revised set of IPA criteria has therefore been developed, based closely on the original criteria but factoring in some of the differing conservation challenges and opportunities and the data limitations that plant scientists and conservationists face outside Europe.

A re-drafted version of the criteria was presented to the global IPA partnership (see Plantlife 2010b; Plantlife International 2010) and to a wide range of organisations and individuals in the scientific, conservation and land management arenas through a consultation period in late 2015. Translations of the drafted criteria were produced in French, Portuguese and Spanish to encourage a broad response from across the stakeholder group. A series of workshops was also held with members of the IUCN Species Survival Commission to explore and attempt to maximise the synergies between the revised IPA criteria and those of the KBAs Standard (IUCN 2016). The aim of this consultation was to produce a scientifically robust set of criteria for identifying IPAs that are applicable globally, with appropriate thresholds and guiding principles and with transparent selection processes, but 
which also acknowledge practical considerations in site selection and the availability of data around the world. The draft criteria were further modified in early 2016 in light of the constructive and helpful feedback received through the consultation period.

The revised global IPA criteria are presented in "The revised IPA selection criteria" section of this paper, together with guidance notes on how to apply them. Several of the criteria that have been formally adopted here have already been tested successfully in previous IPA assessments; for example the modified sub-criteria A(iii) and A(iv) have been used widely in the Mediterranean region (Radford et al. 2011). The new sub-criterion B(ii): "exceptional number of species of high conservation importance", which we envisage may be widely applied in place of criterion B(i) in countries that lack a detailed habitat classification, has been tested using several available datasets for the tropics in order to ensure that the threshold is neither too restrictive nor too easily met; this testing will be presented in a separate publication (Darbyshire et al. in prep.). However, we emphasise that the identification of IPA networks, and the criteria on which they are based, is an iterative process and we will continue to learn from the experiences of applying the IPA approach in new regions and in light of fresh conservation challenges.

In the "Alignment of IPA criteria to IUCN Key Biodiversity Areas" section, we align the revised IPA criteria to those of the KBAs and compare and contrast the two schemes.

\section{Integrating socially, economically and culturally useful plant species into site- based conservation prioritisation}

Perhaps the most notable revision to the IPA criteria is the recognition for the first time of socio-economically valuable plant species as a measure of importance. Plant species that are harvested from the wild for social, economic and cultural use (henceforth useful plant species for the sake of brevity) are of vital importance to the livelihoods of mankind across the globe, providing essential food sources for humans and livestock, medicines, timber, fuel sources, materials for clothing, etc., ornamental species, social and cultural traditions and vital ecosystem services. Over 30,000 plant species are currently listed to have at least one documented use (Canteiro et al. 2016), and many more species have important uses that are currently undocumented in the literature or have yet to be incorporated in major useful plant databases. In addition, the wild relatives of commercial crop species [crop wild relatives (CWRs)] provide an important pool of genetic diversity that can help to improve our crop plants in the future, both through increasing resilience to plant diseases, pests and climate change and through improving production through the selection of desirable traits (Heywood et al. 2007; Maxted et al. 2012). However, useful plant species are also amongst the most threatened groups of plants: "Biological Resource Use" (principally logging and gathering of terrestrial plants) contributes $21 \%$ of the threatening processes for vascular plant species assessed on the IUCN Red List (Bachman et al. 2016).

Despite their obvious importance and despite the imminent threats to many of these species, most site-based conservation prioritisation initiatives do not explicitly include wild harvested useful species as a measure of biodiversity value, except where the species in question are known to be threatened. The case for including useful plant species within such initiatives is nevertheless strong. Not only are they of high value in their own right, because of their importance to human livelihoods, but their inclusion provides a means of facilitating and encouraging wider stakeholder consultation on the identification of key sites for wild plant diversity outside the scientific and protected area communities. Studies have demonstrated a direct positive link between maintaining or enhancing wild biodiversity and human livelihoods and well-being, through the ecosystem services provided by 
ecological communities, habitats and species diversity (Xu et al. 2009; Sunderland 2011; Peh et al. 2013; Fisher et al. 2014; Harrison et al. 2014; Sandifer et al. 2015). However, this link is not widely perceived in many parts of the world and protection of sites of high biodiversity value is only likely to be achieved where there is a clear and demonstrable benefit to local communities. By highlighting the presence of useful plant species within sites of importance to biodiversity, the process is much more likely to engage local communities who live and work within IPAs in their long term protection and sustainable management (Anderson et al. 2016). It is clear that we cannot rely on legal designation of protected areas alone, and that community-led stewardship of many sites is vital if we are to safeguard global biodiversity (Brown and Hay-Edie 2013; Corrigan and Hay-Edie 2013). Both the Aichi Biodiversity Targets (CBD 2012) and the relevant UN Sustainable Development Goals (2015) emphasise this direct and explicit link between conserving biodiversity and improving human livelihoods, and it is important that conservation prioritisation mechanisms also follow this approach.

IPA criteria have already been applied to useful plant species to a limited extent, most notably in the Himalaya where IPAs for medicinal plant species have been identified and documented through a consortium of national scientists and local communities from across the region (Hamilton and Radford 2007). Here, we formally incorporate useful plant species in their broadest sense as an integral part of the IPA identification and selection process for the first time. Identification of IPAs may be based on the presence of individual, threatened and/or range-restricted useful plant species under criterion A (for which we recommend prioritising red listing of useful species threatened on a global or regional basis by over-harvesting or related factors) or on the basis of holding concentrations of wildharvested useful species under sub-criterion B(iii). The species selected as socio-economically valuable for sub-criterion $\mathrm{B}$ (iii) should be amenable to site-based conservation measures; their selection should ultimately be a national decision but based on wide public and institutional consultation (potentially incorporating a regional prioritisation process) so as to encourage local community engagement in the process from the outset and maximise economic/livelihood benefits.

Specific plant uses are, of course, only one of the range of ecosystem services that plant species and their habitats provide. Some evidence suggests that conservation planning focusing on biodiversity alone does not guarantee the protection of the full range of provisioning and regulatory ecosystem services, hence these must be factored into SCP approaches (Manhaes et al. 2016). IPAs, as a national-based system, may not be sufficiently fine-scale to encompass the undisputed need to conserve plants at all spatial scales and the more local ecosystem services they provide such as pollinator food sources. IPAs can, on the other hand, enable better protection of landscape scale ecosystem services-for example water regulation provided by intact forest. In the Himalaya study, for example, the authors concluded that IPAs should be developed for national-level plant conservation processes including landscape-level planning, but that finer scale community-level conservation was essential for medicinal plants (Hamilton and Radford 2007). Interestingly some Himalayan communities within the Himalayas were protecting their own IPAs'Indigenous Plant Areas'.

Ultimately, it may be beneficial to combine the IPA approach with a scheme tailored towards the protection of natural capital. As a first step, national IPA constituencies are encouraged to record the range of ecosystem services that the selected sites provide in addition to the useful plant species that they support. 


\section{The revised IPA selection criteria}

Presented below are the revised global IPA criteria; these are also summarised in Table 1. For each criterion, we present the general goal and guiding principles, then provide detail on the sub-criteria with their corresponding thresholds and notes on their application. We also record how each of the revised sub-criteria relate to the original European IPA criteria set out in the IPA site selection manual (Anderson 2002). Additional information of relevance to the identification and documentation of IPAs can be found in that publication and it is the intention of Plantlife International and Kew to update this manual based on the revised criteria presented here.

\section{General guiding principles of the IPA methodology}

- The IPA criteria are designed to be applicable to algae, hornworts, lichens, liverworts, mosses, vascular plants and fungi; see, for example, Stewart (2004), Perini et al. (2011) and Ravera et al. (2011). It is a decision for the IPA national constituencies as to whether or not plants and fungi are assessed together or considered separately. For example, in the UK the Important Fungus Areas Project (Evans et al. 2001) was separate to the IPAs project, whereas in Belarus, the Czech Republic, Estonia, Romania, and Slovakia, fungi were included in the national IPA network through criterion A (Anderson et al. 2005).

- The selection of sites should be based as far as possible on sound data, quantifiable population and area thresholds, and a transparent selection process, but recognising the important role of peer-reviewed expert opinion at the national and regional level.

- A site can qualify as an IPA if it satisfies one or more of the criteria, i.e., if it satisfies either criterion A, B, or C or any combination of these. Assessors are encouraged to apply all three criteria where sufficient data are available.

- The aim of the IPA Programme is to identify and protect the most important global sites for wild plants. However, the number, size and range of IPAs recognised within each participating country is a national decision, made via a national IPA constituency. The assessment process is two-staged: the first stage is to identify all potentially qualifying sites that meet one or more of the IPA criteria and associated thresholds; the second is for the national IPA constituency to select from amongst these the most important sites, taking into account the full range of considerations for identifying an effective network of sites.

- Consideration should be given to identifying IPAs on sites that qualify under multiple criteria and/or contain multiple qualifying species and/or habitats, in order to focus conservation action.

- National IPA constituencies should make an assessment of their IPAs as a complementary network of sites, rather than identifying sites on an individual, piecemeal basis.

- IPA designation does not necessarily constitute a recommendation for site protection; it also serves as a mechanism to facilitate impact avoidance or improved management of important or vulnerable elements of plant diversity. Thus a comprehensive network of identified sites does not equate to a 'land-hungry' conservation framework.

- Conserving the range of genetic diversity of threatened species and/or those species of economic or cultural value, including CWRs, should be considered when selecting IPAs. 
Table 1 Summary of the revised IPA criteria and sub-criteria

Sub-criterion Threshold

(A) Threatened species

A(i) Site contains one or more globally threatened species

A(ii) Site contains one or more regionally threatened species

A(iii) Site contains one or more highly restricted endemic species that are potentially threatened

A(iv) Site contains one or more range restricted endemic species that are potentially threatened

(B) Botanical richness

B(i) Site contains a high number of species within defined habitat or vegetation types

B(ii) Site contains an exceptional number of species of high conservation importance

B(iii) Site contains an exceptional number of socially, economically or culturally valuable species

(C) Threatened habitat

C(i) Site contains globally threatened or restricted habitat/vegetation type
Site known, thought or inferred to contain $\mathbf{\geq 1 \%}$ of the global population

\section{AND/OR}

$\mathbf{2 5 \%}$ of the national population OR the $\mathbf{5}$ "best sites" for that species nationally, whichever is most appropriate

Site known, thought or inferred to contain $\geq \mathbf{5 \%}$ of the national population, OR the $\mathbf{5}$ "best sites" for that species nationally, whichever is most appropriate

Site known, thought or inferred to contain $\mathbf{\geq 1 \%}$ of the global population

AND/OR

$\mathbf{2 5 \%}$ of the national population, OR the $\mathbf{5}$ "best sites" for that species nationally, whichever is most appropriate

Site known, thought or inferred to contain $\mathbf{2 1 \%}$ of the global population

\section{AND/OR}

$\mathbf{2 5 \%}$ of the national population, OR the $\mathbf{5}$ "best sites" for that species nationally, whichever is most appropriate

For each habitat or vegetation type: up to $10 \%$ of the national resource can be selected within the whole national IPA network

OR the $\mathbf{5}$ "best sites" nationally, whichever is the most appropriate

Site known to contain $\mathbf{2 3 \%}$ of the selected national list of species of conservation importance

OR the 15 richest sites nationally, whichever is most appropriate

Site known to contain $\mathbf{2 3 \%}$ of the selected national list of socially, economically or culturally valuable species

OR the 15 richest sites nationally, whichever is most appropriate

Site known, thought or inferred to contain $\mathbf{2 5 \%}$ of the national resource (area) of the threatened habitat type

OR site is among the best quality examples required to collectively prioritise $\mathbf{2 0 - 6 0 \%}$ of the national resource

OR the 5 "best sites" for that habitat nationally, whichever is the most appropriate 
Table 1 continued

\begin{tabular}{|c|c|}
\hline Sub-criterion & Threshold \\
\hline $\begin{array}{l}\text { C(ii) Site contains regionally threatened or } \\
\text { restricted habitat/vegetation type }\end{array}$ & $\begin{array}{l}\text { Site known, thought or inferred to contain } \mathbf{2 5 \%} \text { of } \\
\text { the national resource (area) of the threatened } \\
\text { habitat type } \\
\text { OR site is among the best quality examples required } \\
\text { to collectively prioritise } \mathbf{2 0 - 6 0 \%} \text { of the national } \\
\text { resource } \\
\text { OR the } \mathbf{5} \text { "best sites" for that habitat nationally, } \\
\text { whichever is the most appropriate }\end{array}$ \\
\hline $\begin{array}{l}\text { C(iii) Site contains nationally threatened or } \\
\text { restricted habitat/vegetation type, AND/OR } \\
\text { habitats that have severely declined in extent } \\
\text { nationally }\end{array}$ & $\begin{array}{l}\text { Site known, thought or inferred to contain } \geq \mathbf{1 0 \%} \text { of } \\
\text { the national resource (area) of the threatened } \\
\text { habitat type } \\
\text { OR site is among the best quality examples required } \\
\text { to collectively prioritise up to } \mathbf{2 0 \%} \text { of the national } \\
\text { resource } \\
\text { OR the } \mathbf{5} \text { "best sites" for that habitat nationally, } \\
\text { whichever is most appropriate }\end{array}$ \\
\hline
\end{tabular}

\section{Key definitions}

We have tried where possible to avoid the use of excessive terminology within the criteria, and any technical terms that are used are explained in the accompanying notes. However, three key terms merit explanation at the outset:

Population the term "population" here refers to the total number of individuals of a species within a discrete geographical unit (site). This correlates to the "sub-populations" in IUCN Red List terminology (2014). In cases where we are referring to the global population of a species, i.e., all of the individuals of that species globally, sometimes referred to as the meta-population in population genetics literature, we use the term "global population"; the same applies to national and regional populations of a species.

Range the range of a species is the known or inferred limits of its distribution. The range thresholds in sub-criteria A(iii) and A(iv) are deliberately aligned to the range thresholds for the Critically Endangered and Endangered categories of IUCN species Red List assessments under criterion B (2012), referred to as extent of occurrence (EOO)-see below. These thresholds are $<100 \mathrm{~km}^{2}$ for $\mathrm{A}$ (iii) and $>100 \mathrm{~km}^{2}$ but less than $5000 \mathrm{~km}^{2}$ for A(iv). The definition of "restricted range species" in sub-criterion $B(i i)$, set at $10,000 \mathrm{~km}^{2}$, is aligned to the definition of restricted range in the KBA Standard that we consider most likely to be applied to plant species (IUCN 2016).

There are a number of ways in which a species' range can be defined (see, e.g., Gaston and Fuller 2008) and we do not wish to be overly prescriptive in how this should be calculated, as it will depend in part upon how much data are available for a particular species as to how accurately the range can be calculated. However, for most species, particularly in regions of limited data availability, we would recommend using the minimum convex polygon (MCP) approach to calculating EOO as a measure of range as defined in the IUCN Red List Categories and Criteria (see IUCN Standards and Petitions Subcommittee 2014; Joppa et al. 2016). This can be readily calculated using the GeoCAT online tool (Bachman et al. 2011) so long as georeferenced occurrence data are available for the species in question. EOO using MCP will tend to over-estimate the true range of a species, particularly when concerned with species that have highly specific and/or 
restricted habitats, but this over-estimation is factored into the range thresholds used in the IPA criteria.

Region a region is defined as a multi-country area where it would be beneficial to work across national boundaries to share skills, build networks, define conservation risk and plan conservation action. For example Europe was recognised as a region in IPA projects (Anderson 2002; Anderson et al. 2005; Radford and Odé 2009) and North Africa and the Middle East was also considered as a region for IPA identification and conservation (Radford et al. 2011).

Restricted habitat this is a habitat or ecosystem recognised as having a restricted range at a given geographic scale (global, national, regional). At the global scale, this can be informed by the EOO or area of occupancy thresholds for "restricted geographic distribution" used in criterion B of the IUCN Red List of Ecosystems (Bland et al. 2015). It is difficult to provide an absolute definition of a restricted habitat at the national level given the many different habitat classifications in use and the difficulties of using a percentage of national area in countries with very different sizes. We encourage national IPA constituencies to include a description and justification of habitats included in their threatened or restricted lists as part of the transparent IPA selection process and to engage with the ongoing IUCN assessment of global ecosystem threat.

\section{Criterion A: threatened species}

Goal to capture populations of the most threatened plant and fungal species on a global or regional scale. Highly range-restricted species are recognised as inherently threatened (e.g., by stochastic processes) when insufficient data or capacity means their threat status has not been formally assessed.

Guiding principles for criterion A:

- The national IPA network should represent the full range of species on the national criterion A species list.

- Where data are available, sites that contain a significant proportion of the global (or regional) population of a species should be included in the IPA network.

- The national constituency should select up to five sites per criterion A species, either from amongst the sites that meet the criterion threshold or, in the absence of the required population data, through selection of the five "best" sites based on expert consensus. In exceptional cases, for example where there are fewer than 10 sites in the whole country or where there are between 5 and 10 known large populations of a species, up to 10 sites may be selected per species in each country. The population thresholds are set necessarily low as in certain cases even relatively small populations can be of high conservation importance, particularly where they are geographically/genetically isolated or edge-of-range populations and/or are in secure, well-protected sites. However, it is not intended that every site that meets the population threshold for every criterion A species should qualify as an IPA.

- For particularly dispersed criterion A species with no obvious population centres, separate IPAs should not be selected for those species alone when it is possible to include them within IPAs selected primarily on the basis of other species or criteria.

- The degree of threat to the population and the need for protection should be taken into account in the IPA assessment and fully documented. IPAs should be selected only for populations that are viable or for which there is hope that ameliorative measures can be taken to ensure a return to viability. 
- IPA sub-criteria A(iii) and A(iv) take account of the lack of formal global conservation status assessments for the large majority of plant and fungi species, due both to limited capacity and limited data availability, by using extreme range-restriction as a proxy for threat in the absence of a full assessment.

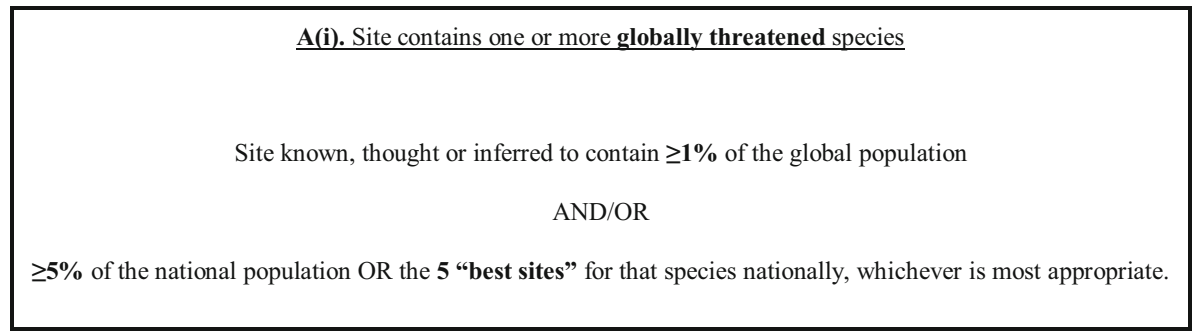

Notes on the application of sub-criterion A(i):

(1) Qualifying species must be listed as threatened [vulnerable (VU), endangered (EN) or critically endangered (CR); IUCN 2012] on the IUCN global Red List (www. iucnredlist.org) or, if relevant or appropriate, the 1997 IUCN Red List of Threatened Plants (Walter and Gillett 1997).

(2) It is acceptable to include those species assessed as threatened and accepted by the IUCN review process but awaiting upload onto the IUCN Red List. For example, species awaiting upload from the IUCN species information system (SIS) following review can be included, as can species with assessments that have been reviewed by an IUCN-approved reviewer but have not yet been entered into SIS.

(3) Wherever possible, both the global and national importance of the site should be documented by applying the \% population thresholds for each threatened species; the selection of "best sites" should only be applied where population data are not available and cannot be inferred.

(4) If the IPA contains a single-site, threatened (CR or EN) endemic species, i.e., the site effectively holds the entire global population of that species, this should be recorded in the site documentation to assist with alignment to KBA criteria.

(5) A(i) species of high socio-economic importance (nationally, regionally or globally) can be tagged as such to facilitate subsequent analysis focused on useful species.

This sub-criterion is largely identical to the regional approach to IPA identification in Europe (Anderson 2002), but with two additions. First, species that have been assessed as threatened according to IUCN criteria and reviewed but have not yet been uploaded to the official global Red List are accepted as criterion A(i) species-this is a pragmatic decision because of the periodic release of reviewed species to the Red List and the resultant time lag which may otherwise delay the IPA assessment process. Second, a global population threshold for each threatened species is included for the first time; this will provide stronger evidence for the global importance of the IPA site in addition to its national importance. It also helps to align this sub-criterion to KBA criterion A (see "Alignment of IPA criteria to IUCN Key Biodiversity Areas" section). 


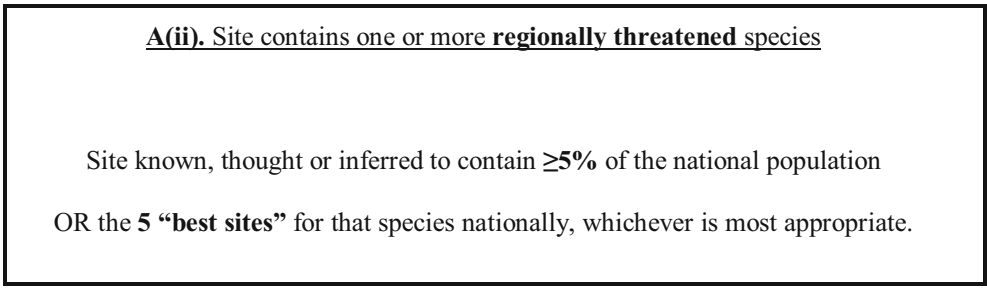

Notes on the application of sub-criterion A(ii):

(1) Qualifying species must be listed as threatened on an IUCN Regional Red List OR another regionally approved, peer-reviewed threat list, for example the threatened medicinal plants of the Himalaya (Hamilton and Radford 2007).

(2) Note (5) for sub-criterion A(i) is equally applicable here.

This sub-criterion is virtually identical to the detailed regional approach for IPA identification in Europe. In Europe the regionally threatened species are those contained within the annexes of the EU Habitats Directive: Annex II (European Union 1992) and Bern Convention: Appendix 1 (Council of Europe 1979).

In the Tropics we do not foresee that this sub-criterion will be widely applied, but it may be applicable to particular species of regional importance, for example highly important socio-economic species that are considered to be regionally threatened and published as such.

$\underline{\text { A(iii). Site contains one or more highly restricted endemic species that are potentially threatened }}$

Site known, thought or inferred to contain $\geq \mathbf{1} \%$ of the global population

$\mathrm{AND} / \mathrm{OR}$

$\mathbf{\geq} \mathbf{5 \%}$ of the national population OR the $\mathbf{5}$ "best sites" for that species nationally, whichever is most appropriate.

$\underline{\text { A(iv). Site contains one or more range restricted endemic species that are potentially threatened }}$

Threshold as per A(iii)

Notes on the application of sub-criteria A(iii) and A(iv):

(1) A "Highly Restricted Endemic" (HRE) is defined as a species with a total range of $<100 \mathrm{~km}^{2}$. A "Range Restricted Endemic" (RRE) is defined as a species with a total range of $<5000 \mathrm{~km}^{2}$ but $>100 \mathrm{~km}^{2}$. These definitions of "highly restricted" and "range restricted" are aligned respectively to the CR and EN range (EOO) thresholds for IUCN threat assessments under criterion B (2012). Hence, in effect, the species are defined through partial assessment against IUCN criterion B but without the need to determine fully the threat status; it is a step towards improving 
the information on threatened species within these regions. Endemism is defined by ecological range size rather than by political borders, and thus $\mathrm{A}$ (iii) and A(iv) species can have trans-border ranges. A(iii) and A(iv) are recorded separately to allow for more detailed analysis of sites and species; they share the same thresholds.

(2) Species should be listed as HREs or RREs on a recognised national or regional list that can be developed, peer-reviewed and published as part of the IPA identification process.

(3) HREs and RREs that have already been assessed on the IUCN Red List are excluded from these sub-criteria except where listed as Data Deficient. If they have been assessed as threatened (VU, EN or CR), they should be considered under subcriterion A(i); if assessed as least concern or near threatened, they should be included in the species list for sub-criterion B(ii).

(4) Notes (3)-(5) for sub-criterion A(i) are equally applicable to sub-criteria A(iii) and $A(i v)$. In addition, where a site is known or inferred to contain $\geq 10 \%$ of a HRE or $\mathrm{RRE}$, this should be recorded in the site documentation to assist with alignment to KBA criteria.

Sub-criteria A(iii) and A(iv) are defined differently from those used within Europe (Anderson 2002). The corresponding European IPA sub-criteria focus on threatened national endemics and national near-endemics respectively, using political boundaries because countries are typically smaller and suitable threat data, in the form of national red lists, are often available within Europe. Beyond Europe, countries are often larger (although we acknowledge that there are also small countries in the tropics) and national red lists do not often exist.

The concepts of HREs (then called Site Restricted Species) and RREs (then called Restricted Range Species) were first introduced into IPA methodology in a project in North Africa and the Middle East (Radford et al. 2011). They are formally adopted here. We have replaced "Site Restricted" with "Highly Restricted" as we acknowledge that not all species with a range of $<100 \mathrm{~km}^{2}$ are restricted to a single site.

\section{Criterion B: botanical richness}

Goal to capture sites of exceptional plant and fungal diversity, focussing on high-quality species assemblages, irrespective of threat.

This is achieved by selecting sites that contain high concentrations of species that indicate either high-quality habitat and/or species-rich sites. Where data are available, the richest sites per habitat can be selected; this is possible for data-rich countries where there is a strong understanding of the full range of habitat types and their species assemblages. Where species data for habitats are not systematically available, the richest sites are chosen on the basis of high concentrations of important/valuable species; this approach is likely to be more appropriate for use in most of the tropics. The sub-criteria B(ii) and B(iii) have been separated because they reflect different value systems for important species: B(ii) emphasises species of value because they are rare and irreplaceable species and/or indicators of important habitats and sites, whilst B(iii) emphasises species of socio-economic value to humans including those that have cultural or spiritual value. However, these two species lists are not mutually exclusive.

Guiding principles for criterion B:

- The concept of complementarity should be applied wherever possible and practical: sites selected under criterion B should attempt to include the greatest number of 
different species rather than selecting multiple sites which contain largely the same species assemblages.

- Where practical, the creation of a list of indicator species for good-quality, botanicallyrich examples of a particular habitat (e.g., peat bog, dry grassland, coastal dry forest) is a means of rapidly measuring and comparing richness at sites of that habitat type using sub-criterion B(i).

- Creating a national list of the most 'valuable' species, focussing on globally rangerestricted species [sub-criterion B(ii)] and/or nationally or regionally important wildharvested socio-economic species [sub-criterion $\mathrm{B}$ (iii)] is a means of measuring and comparing botanical richness where limited data sets are available. We strongly recommend that IPA assessors apply EITHER sub-criterion B(i) OR sub-criterion B(ii), not both. Sub-criterion B(iii) can be applied in all cases.

- Creating indicator lists of valuable wild-harvested socio-economic plants is a means of facilitating and encouraging wider stakeholder consultation on the identification of key sites for wild plant diversity outside of the scientific and protected area communities.

B(i). Site contains a high number of species within defined habitat or vegetation types

For each habitat or vegetation type:

Up to $10 \%$ of the national resource can be selected within the whole national IPA network

OR the $\mathbf{5}$ "best sites" nationally, whichever is the most appropriate.

Notes on the application of sub-criterion B(i):

(1) The development and use of national indicator species for each habitat/vegetation type is encouraged, given sufficient data. Indicator species chosen for B(i) should be characteristic species that indicate good quality habitat: axiophytes (see Lockton 2005; Botanical Society of Britain and Ireland 2016).

(2) Botanical richness is linked to habitats in this sub-criterion to give an indication of habitat quality-the best peat bogs, the best chalk grasslands, etc., since it is important to compare like with like. Sites that have exceptional richness because they hold a mosaic of habitats within a small area should be identified using B(ii) below.

(3) This sub-criterion should only be applied for defined habitats where there is a sufficient level of information on species composition in order to determine habitat quality. It is likely to be difficult to apply systematically in many tropical countries, where habitat classifications at an appropriately fine scale and lists of indicator species for habitat quality often do not currently exist. In these cases, sub-criterion B(ii) is likely to be more appropriate-assessors should apply either B(i) or B(ii), not both.

This sub-criterion is identical to criterion B used for European IPAs (Anderson 2002) but with increased emphasis on the recommendation to use species that indicate good quality habitat, and the proviso that this sub-criterion should only be used where there are data of sufficient quality and resolution. 
B(ii). Site contains an exceptional number of species of high conservation importance

Site known to contain $\geq \mathbf{3} \%$ of the selected national list of species of conservation importance

OR the 15 richest sites nationally, whichever is most appropriate.

Notes on the application of sub-criterion B(ii):

(1) B(ii) species can be selected from the following categories: (a) restricted range species, defined as those with a total range of $<10,000 \mathrm{~km}^{2}$ (note: species also qualifying under IPA criterion A are NOT excluded), (b) national endemic species, (c) national Red List species not covered by criterion A. It is not obligatory to include all of the categories $(\mathrm{a}-\mathrm{c})$. The possible inclusion here of national endemics - defined by political borders-is not without controversy, but we acknowledge that national endemic species can be of importance in conservation planning and so should be recognised as species of high conservation importance. The decision as to which species groups from (a) to (c) are chosen for applying this sub-criterion should be made by the national IPA constituency.

(2) Lists of species used should be published and justified as part of the IPA identification process.

(3) The species list can comprise qualifying species from the total flora or mycota of the country, or the qualifying species from one or more taxonomic groups (for example, a plant family) that is/are representative of the wider flora or mycota and so can be used as proxy group(s) for measuring exceptional richness.

(4) There is no prescriptive minimum number of species for a site to qualify as this will depend in part on the richness of the national flora or mycota and of its species of high conservation importance, but the site should be exceptional at a national scale; this judgement can be made by the national IPA constituency.

(5) Sites selected should have reasonable ecological and geographical integrity, whether a habitat mosaic or otherwise, and should not be greater than $1 \%$ of the area of the country or $50,000 \mathrm{~km}^{2}$, whichever is the smaller.

This is a new sub-criterion, not previously applied in any IPA context.

B(iii). Site contains an exceptional number of socially, economically or culturally valuable species.

Site known to contain $\geq \mathbf{3} \%$ of the selected national list of socially, economically or culturally valuable species

OR the 15 richest sites nationally, whichever is most appropriate.

Notes on the application of sub-criterion B(iii):

(1) B(iii) species can be selected from the following categories and should focus on those species that would benefit from site-based conservation measures: (a) socioeconomically important wild-harvested species, including medicinal plants, food 
plants, resin/dye plants, timber species, etc., (b) CWRs, (c) other culturally and spiritually important plants; (d) CITES species listed on Appendix 1 or Appendix 2 (excluding plant groups where whole families/genera are listed on Appendix 2 such as orchids, Aloe spp., succulent Euphorbia spp.).

(2) A list of B(iii) species should be published and justified as part of the IPA identification process. Naturalised alien species should not be included on this list except where a strong case can be made for their inclusion (e.g., thoroughly naturalised archaeophytes); this is a decision for the national IPA constituency.

(3) Notes (4) and (5) for sub-criterion B(ii) equally apply here.

This is a new sub-criterion, not previously applied in any IPA context.

\section{Criterion C: threatened habitat}

Goal to capture the largest, most intact areas of threatened and/or extremely restricted (and thus highly likely to be threatened) natural or semi-natural habitats, and severely declining habitats that may once have been common. This is regardless of how botanically rich they are.

Guiding principles for criterion C:

- The national IPA network should represent the full range of national criterion $\mathrm{C}$ habitats.

- The threshold for selecting IPAs is based on area in order to preserve the largest continuous extents of each habitat. However, factors such as land management history, habitat quality (health and integrity) and species diversity can also be considered in site selection. The thresholds apply to the remaining extent of the habitat type as opposed to the potential extent.

- It is important to note that sub-criteria C(i)-C(iii) do not distinguish between threatened and restricted habitat. This is a pragmatic (not a theoretical) decision because in many countries outside Europe there are no official threatened habitat lists and a habitat may be referred to as threatened because it is restricted and/or infrequent and/or declining. Within Europe the distinction is clearer but as fragmentation of habitats is so much more acute, restricted and infrequent habitats are more likely to be threatened, and regional lists of threatened habitats are available. Where limited habitat/vegetation data exist, IPA identification can begin the process of developing habitat data resources in each country based on expert opinion, using sub-criterion $\mathrm{C}(\mathrm{iii})$. In cases where it is possible to identify globally restricted habitats, these should be captured under subcriterion C(i).

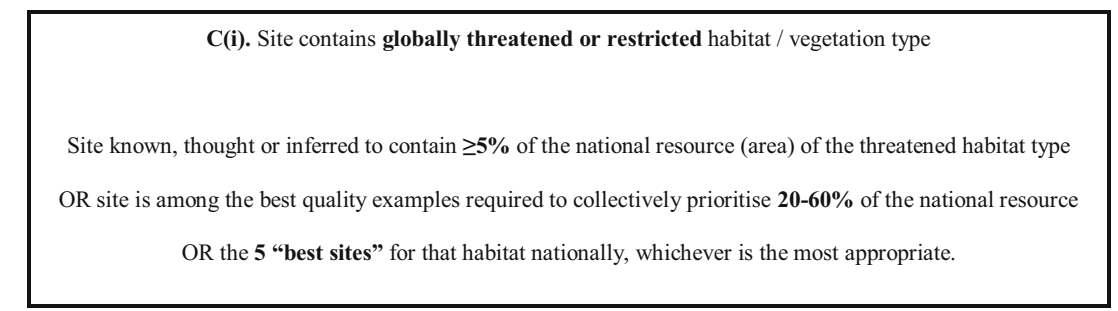

Notes on the application of sub-criterion C(i): 
(1) C(i) threatened or restricted habitat/vegetation types are taken from a globally recognised list, potentially following the categories and criteria of the IUCN Red List of Threatened Ecosystems (Bland et al. 2015). This list does not exist at present but may do in future so is included to 'future-proof' the criteria.

(2) The 20-60\% threshold is derived from the EU Habitats Directive for priority threatened habitats and so may not be appropriate for use outside Europe, where the $\geq 5 \%$ threshold may be more appropriate.

(3) Wherever possible, the national importance of the site should be documented by applying the threshold for the \% of the national resource; the selection of "best sites" should only be applied where quantitative data are not available and cannot be inferred.

(4) In addition to meeting the national thresholds, if the site is known or inferred to contain $\geq 5 \%$ of the global extent of a globally Endangered or Critically Endangered habitat/vegetation type, $\geq 10 \%$ of the global extent of a globally Vulnerable habitat/ vegetation type, or $\geq 20 \%$ of the global extent of a geographically-restricted habitat/ vegetation type regardless of threat status, then this should be recorded in the site documentation to assist with alignment to KBA criteria.

In the European IPA criteria, C(i) refers to priority threatened habitats on the EU Habitat Directive (1992). Globally threatened or restricted habitats were not considered, hence this is an additional sub-criterion albeit one that cannot be applied systematically until an appropriate list is developed. Existing European IPAs identified on the basis of sub-criterion C(i) of the original IPA criteria can be reclassified as C(ii) sites in a future iteration of the IPA database.

C(ii). Site contains regionally threatened or restricted habitat / vegetation type

Site known, thought or inferred to contain $\geq \mathbf{5 \%}$ of the national resource (area) of the threatened habitat type

OR site is among the best quality examples required to collectively prioritise $\mathbf{2 0 - 6 0 \%}$ of the national resource

OR the $\mathbf{5}$ "best sites" nationally, whichever is the most appropriate.

Notes on the application of sub-criterion C(ii):

(1) C(ii) restricted or threatened habitats or vegetation types are taken from a regionally recognised list. This list can be developed, peer-reviewed and published as part of the IPA identification process if neighbouring countries are involved.

(2) Notes (2) and (3) for sub-criterion C(i) equally apply here.

This sub-criterion is identical to criterion $\mathrm{C}$ in the European IPA criteria, which was split into C(i)—EU Habitats Directive priority habitats, and C(ii)—remaining EU Habitats Directive habitats or Bern Convention habitats (Council of Europe 1979; European Union 1992). 
C(iii). Site contains nationally threatened or restricted habitat / vegetation type, AND/OR habitats that have severely declined in extent nationally

Site known, thought or inferred to contain $\geq \mathbf{1 0} \%$ of the national resource (area) of the threatened habitat type OR site is among the best quality examples required to collectively prioritise up to $\mathbf{2 0} \%$ of the national resource

OR the $\mathbf{5}$ "best sites" nationally, whichever is the most appropriate.

Notes on the application of sub-criterion C(iii):

(1) C(iii) restricted or threatened habitats or vegetation types are taken from a nationally recognised list. This list can be developed, published and peer reviewed as part of the IPA identification process. A good example of this is the nationally threatened habitat list of Armenia (Asatryan and Fayvush 2013).

(2) Habitats that have "severely declined in extent" are defined as those that have declined in extent by $50 \%$ or more nationally since 1900 .

(3) This sub-criterion will capture the most intact examples of those habitats that are threatened or highly restricted or severely declining within the country (and potentially more widely). It can also capture those habitats that have a nationally restricted range, even though they are more common elsewhere, if they are an important national resource and/or they are important as 'edge of range' examples.

(4) This sub-criterion is more appropriate to use in larger and/or data poor countries where data are held at a national level-in time it will help countries obtain a greater understanding of threatened/restricted habitats in their countries and how they relate to the wider regional and/or global picture.

(5) Note (3) of sub-criterion C(i) equally applies here.

This is a new sub-criterion, not previously applied in any IPA context.

\section{IPA selection, size and boundaries}

IPAs can be identified on any land regardless of their designation, e.g., private, public or protected. There is no fixed minimum or maximum size for IPAs, however the site should have reasonable ecological/geographical integrity and an IPA site should feasibly be a viable conservation management unit. Therefore, extremely large IPAs that could not be managed as a single unit are not desirable except in exceptional circumstances (e.g., large extents of pristine criterion $C$ habitats). A maximum size guide could be less than $1 \%$ of the area of the country or $50,000 \mathrm{~km}^{2}$. An IPA should be defined so that as far as possible it is different in character or habitat or botanical significance from the surrounding area. As the ultimate aim of an IPA programme is to ensure the long-term conservation of the most important sites for plant diversity, an IPA should have the potential to be managed to protect the botanical interest of the site and/or ensure its sustainable use. However, we acknowledge that it may not always be practical or even appropriate to establish an IPA as a formal protected area. A pragmatic approach to support the long term conservation of each IPA should be made by local stakeholders. 
There are no set rules for the treatment of sites that lie close to each other. These could remain as individual IPAs or could be merged to create a single larger IPA. As a practical example, the mapping process for the large, interlinked West Coast IPA in Scotland is available (Fraser and Winterbottom 2010). The possibility of linking sites through ecological corridors, to prevent isolation of populations and to build resilience against the effects of climate change, should also be considered in the final selection of IPAs.

For the delimitation of site boundaries, obvious barriers such as rivers, roads or distinct changes in land use can be used where they are considered appropriate. In larger regions where there are less obvious site boundaries or changes in habitat type, site boundaries can be delimited by geological features such as ridge-lines or hilltops. As with the selection of sites, the final decision as to the boundaries of each IPA lies with the national IPA constituency. Where possible and desirable, IPAs should have buffer zones or Zones of Opportunity (areas where habitat restoration can potentially be applied and isolation of species or habitats be prevented) defined around the core IPA zone. A decision tree for deciding site boundaries and identifying Zones of Opportunity has been developed for the UK IPA network (Dines and Hutchinson 2008) and elements of this could be applied more widely.

The degree of threat and the need for protection should be considered in the selection process and fully documented if the site is selected as an IPA. IPAs that fall wholly or partially within existing protected areas do not necessarily have to match the size or boundary of that protected area.

\section{Alignment of IPA criteria to IUCN Key Biodiversity Areas}

KBAs are defined as sites of importance for the global persistence of biodiversity (IUCN 2016). The concept of KBAs has been in use for some time (Eken et al. 2004; Langhammer et al. 2007), and widely employed in a number of geographical regions (e.g., Eken et al. 2004; Gerlach 2008; Kasecker et al. 2009; Paese et al. 2010; Melovski et al. 2012) and ecological zones such as freshwater ecosystems (Holland et al. 2012; Carrizo et al. 2014). However, a fully standardised methodology for their identification, based on a single set of criteria for all organism groups with strict quantitative thresholds - the KBA Standardhas only recently been launched (IUCN 2016). One of the stated aims of the KBA Standard is to harmonise existing approaches to the identification of important sites for biodiversity, including Important Bird and Biodiversity Areas (BirdLife International 2014), the Alliance for Zero Extinction (Ricketts et al. 2005), PBAs (van Swaay and Warren 2006) and IPAs. A single standardised approach has considerable merit, particularly in terms of rapidly and simply conveying information on priority sites for biodiversity under a single banner to a range of key stakeholders both within and beyond the scientific world. However, there is still a need for the more tailored approach that IPAs provide for plants, for several reasons:

(1) Plants are diverse in orders of magnitude greater than many of the more exhaustively studied organism groups, such as birds and mammals, on which many site-based prioritisation methodologies (including KBAs) have been based. As a direct result of this, plant conservationists face major limitations in terms of available data on species distributions, population sizes and threats, and the capacity and resources to gather such data. Whilst being scientifically robust and transparent, the IPA methodology is also pragmatic and flexible, factoring in these data and capacity 
limitations such that the criteria are readily applicable in both data-rich and datapoor regions. For example, through the option to select the "best"/"richest" sites based upon the data available, IPAs can be assessed in the absence of comprehensive population (for species) or area (habitat) data.

(2) The conservation of plant diversity and plant habitats is of such fundamental importance to the safeguarding of wider biodiversity and human livelihoods that sites of prime importance for plant diversity warrant particular recognition and promotion through a dedicated and tailored system.

(3) The IPA methodology is an established, internationally proven method for identifying key sites for plant diversity, in use since 2001. It has been successfully tested on countries and regions with a wide range of plant diversity, from the Falklands Islands, with 180 species of vascular plant 14 of which are endemic (Upson 2012; Upson et al. 2016), to Turkey, with nearly 9000 species of vascular plant, over 3000 of which are endemic (Byfield et al. 2010). Further, it has been tested on countries with varying degrees of data availability, ranging from data-rich countries such as the UK to relatively data-poor countries such as Egypt. With the relatively minor modifications proposed here, the criteria will be readily applicable globally, and through targeting specific countries we can identify site-based priorities for plants in the parts of the world where this information is needed most urgently.

(4) Providing a clear link between biodiversity conservation and human livelihoods is fundamental to driving conservation action and sustainable management in many parts of the world. Under the revised criteria, IPAs explicitly accommodate wildharvested useful species and crop genepools as a measure of biodiversity value, thus providing this clear link and helping to conserve those species that support livelihoods and ecosystem services. Given the increasing recognition of the role of local (stakeholder) communities in sustainable conservation action, this also stands to benefit sustainable long-term outcomes.

The ultimate aim of an IPA programme is to ensure the long-term protection of national IPA networks and their priority species and habitats. With this in mind, national and subnational decision making and conservation practices are factored into the site identification process, and national IPA constituencies are empowered to identify the species, habitats and sites that they consider to be of global importance within their national boundaries. Effective conservation decision-making and implementation is typically based on national priorities, in which case a high level of engagement at the national level is likely to lead to more sustainable conservation impacts.

The KBA Standard, on the other hand, applies strictly global criteria and intentionally omits national priorities and criteria from the identification of KBA sites. This has the advantage of allowing for comparability across all KBA sites so that any KBA site can confidently be said to be of global importance for biodiversity so long as it meets the thresholds of the strict criteria. However, as noted in the "Introduction" section, this approach may serve to exclude many sites that are of global importance for the conservation of a particular plant species or habitat. As an example, when applying an earlier iteration of the KBA criteria to IPAs and IBAs in Macedonia, Melovski et al. (2012) found that 5 of the 42 IPAs and 9 of the 24 IBAs did not meet the KBA criteria despite the sites having international significance. Further, KBA processes are less accommodating of the pragmatic approach needed to identify key sites for data-poor and highly diverse organism groups such as plants, particularly in the tropics. With this comes a concern that exclusive 
reliance on KBAs, identified using well known data-rich species groups, will inadvertently limit progress on plant conservation priorities, and potentially result in their continued under-representation in planning and management schemes.

Rather than being in competition, however, the IPA and KBA programmes should be viewed as both complementary and mutually supporting. Their complementarity derives from their subtly different aims and scope as discussed above. In terms of their mutual support, national IPA programmes will play a major role in providing data towards plantbased KBA assessments. Indeed, many IPAs will automatically qualify as KBAs where the criteria align. At the same time, KBA programmes will support IPA initiatives through providing site-based data on habitats, threats and management practices for other organism groups which will feed into the IPA assessments. Further, the detailed KBA criteria provide clear guidance on the range and detail of data (e.g., species population surveys, detailed habitat mapping) that plant conservationists should strive towards as our understanding of plant diversity develops through increased baseline surveys and site and species monitoring. The identification of national IPA networks is as an essential step in this process.

Ultimately, having a range of available methodologies for assessing conservation priorities, supported by a range of practitioners who have experience in applying these methods and the associated data requirements, is healthy as no one system will be suitable or optimal in every situation.

\section{Detailed comparison of IPA and KBA criteria}

An alignment of the revised IPA criteria with the global KBA criteria is presented in Table 2. In some areas, notably IPA criteria A and C(i), the criteria readily align, subject to the application of global population percentage (species) and range extent (habitat) data, where available, for sites. Wherever feasible, these population and range data will be captured in the IPA database (Plantlife 2010a) to facilitate the future assessment of plantbased KBAs on the basis of IPA data. We have focussed on KBA criteria A and B in the comparison, as these are the most readily applicable to plants. Of the remaining KBA criteria, $\mathrm{C}-\mathrm{E}$, it is possible that criterion $\mathrm{C}$ : ecological integrity could most readily be applied using plant data. However, this requires the ability to identify "one of $\leq 2$ sites per ecoregion characterised by wholly intact ecological communities..." and for most ecoregions, insufficient data are available on plant assemblages to contemplate applying this criterion.

In its first iteration, the IUCN KBA Standard is a global assessment tool, but it is noted that "some countries/regions may also desire to apply the criteria with less stringent thresholds to identify sites of national/regional significance" (IUCN 2016, p. 4) and these thresholds can be set by national constituencies. This is positive, but we would argue that all IPAs are globally important for plant conservation, regardless of whether or not they meet the KBA definition of global importance. Nevertheless, we note in Table 2 the areas where IPA criteria can be aligned to national or regional KBA criteria where the IPAs are assessed only against regional or national criteria [IPA sub-criteria A(ii), C(ii) and C(iii)].

The arrangement of the criteria is somewhat different in the two approaches. IPAs treat individual threatened and/or range restricted species together (criterion A) but separately from threatened and/or range restricted habitats (criterion C). In KBAs, threatened species and habitats are grouped under criterion A: threatened biodiversity, but separate from range-restricted species and habitats which are treated under criterion B: geographically restricted biodiversity. This difference is a result of the practical consideration of limited 


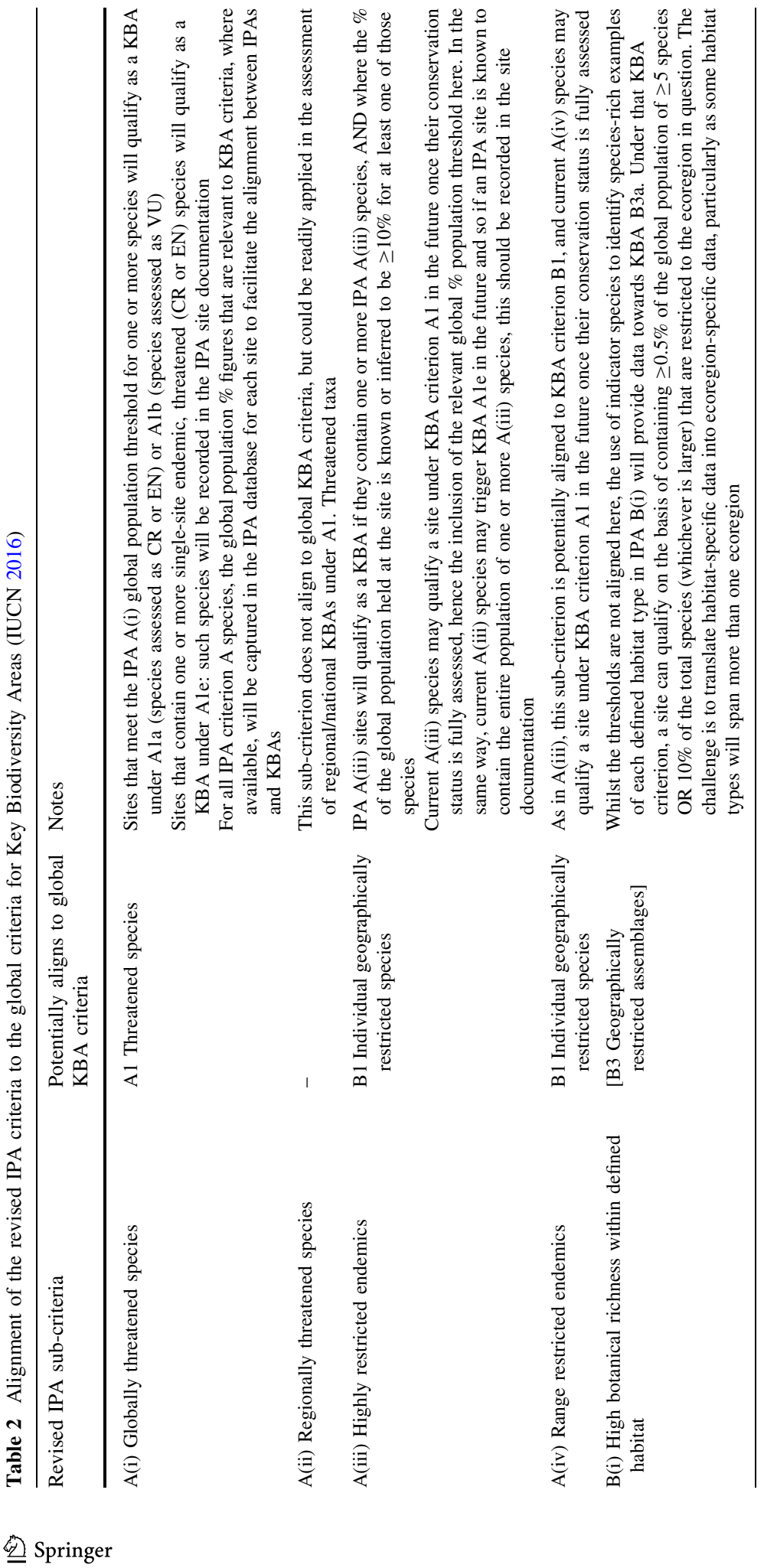




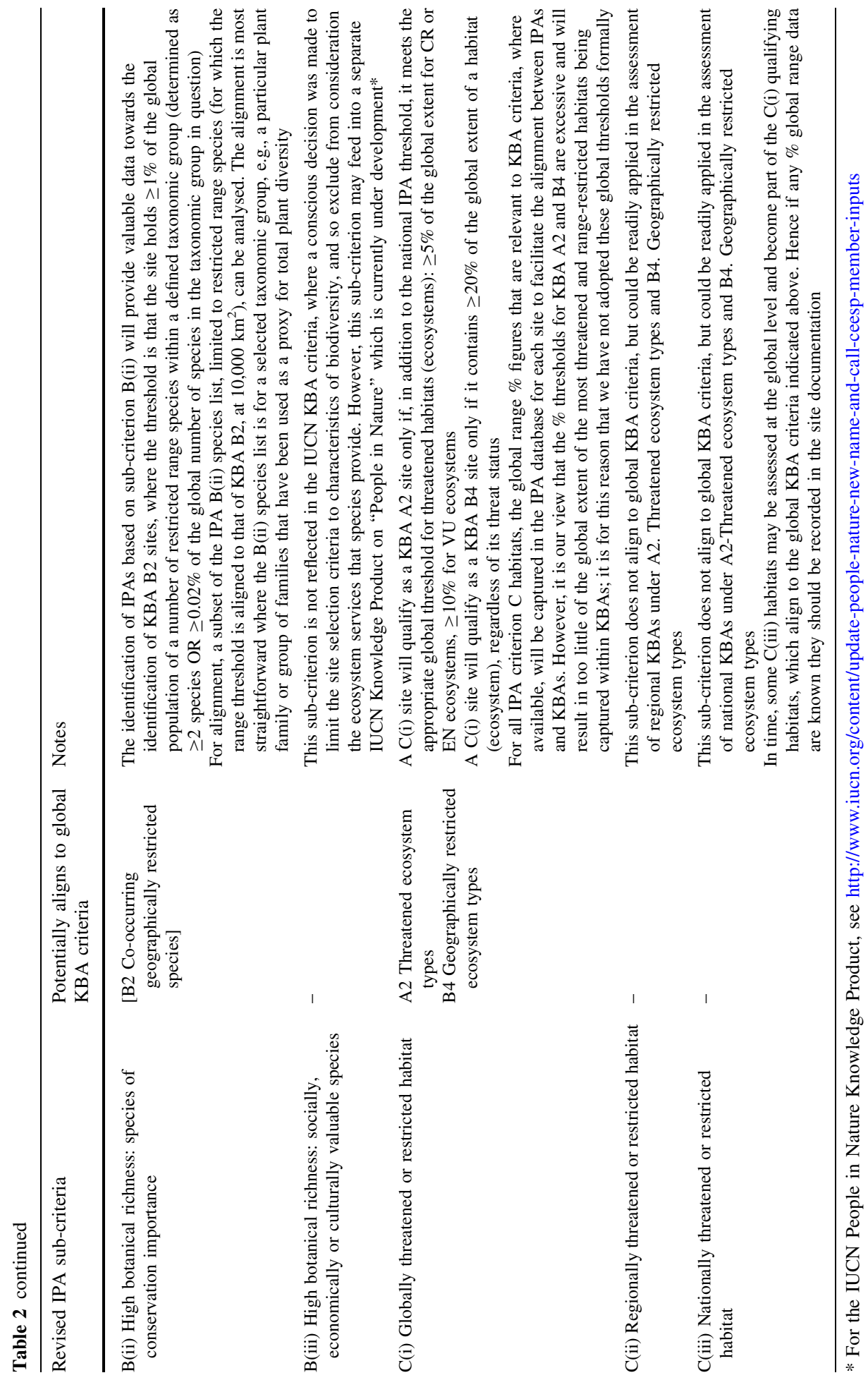


data availability for plants: for both plant species and habitats it is difficult to decouple threat from range restriction as most species and habitats have not had their conservation status assessed and, in many instances, the most range-restricted species or habitats are likely to prove to be the most threatened following a full assessment.

\section{Conclusions}

Identification of sites of importance for plant diversity through the application of IPA criteria has proved a popular and successful approach in Europe, North Africa and the Middle East. The revised criteria presented here incorporate a series of changes identified and recommended following workshops and wide consultation with diverse stakeholders. The revisions are designed to facilitate the extension of IPA identification to countries around the world, including the tropics where uptake to date has been limited. Key changes include (i) the addition of socially, economically and culturally valuable plants as a measure of importance of a site, (ii) an increased emphasis on assemblages of rangerestricted species and other indicator species of high conservation importance as measures of botanical richness, (iii) the inclusion of both nationally and globally threatened habitats as a measure of importance to reflect the varying degree of information held for habitats beyond Europe, and (iv) the removal from the criteria of specific references to or compliance with regional (European) legislation.

The accessible, participatory and nationally-defined nature of the IPA approach, widely recognized as its key strengths, remain central to the IPA identification process.

The principles and thresholds of the IPA criteria proposed here, and the data that will be mobilised through IPA programmes are, in many cases, well aligned with those adopted for the identification of IUCN KBAs, thus optimizing the flow of information between the two systems, and providing mutual support for these important initiatives.

The new criteria will be adopted and implemented in the TIPAs programme over the next 5 years (Anderson et al. 2016; RBG Kew 2016). We very much hope that this will stimulate other countries and regions around the world to initiate, revive or continue their IPA programmes so that a truly global network of IPAs can be identified and managed, helping to safeguard the future of global plant diversity.

Acknowledgements We thank the network of IPA partners in the 69 countries across the globe who are or who have been involved in IPA identification, documentation and ongoing conservation efforts. We are highly grateful to all those individuals and organisations who contributed to the consultation on the revised IPA criteria and all those who have offered their support to this initiative. We are also grateful to the support received from our many colleagues at the Royal Botanic Gardens, Kew and Plantlife International who have fed ideas into this process and to the Tropical Important Plant Areas Programme. Special thanks should be given to the following Kew staff members who kindly translated the consultation documents: Laura Martinez-suz, Carolina Tovar, Julia Carretero and Maria Alvarez (Spanish translation), Cátia Canteiro (Portuguese) and Aurelie Grall and Alex Monro (French); and to Justin Moat who produced the map presented in Fig. 1. We thank Penny Langhammer, Annabelle Cuttelod, Thomas Brooks, Natasha Ali and Simon Stuart of the IUCN Species Survival Commission for their input into the positive and fruitful discussions on synergies between the IPA and KBA methodologies.

\section{Compliance with ethical standards}

Conflict of interest The authors declare that they have no conflict of interest.

Open Access This article is distributed under the terms of the Creative Commons Attribution 4.0 International License (http://creativecommons.org/licenses/by/4.0/), which permits unrestricted use, distribution, 
and reproduction in any medium, provided you give appropriate credit to the original author(s) and the source, provide a link to the Creative Commons license, and indicate if changes were made.

\section{References}

Al-Abbasi TM, Al-Farhan A, Al-Kuhlaidi AW, Hall M, Llewellyn OA, Miller AG, Patzelt A (2010) Important Plant Areas in the Arabian Peninsula. Edinb J Bot 67:25-35. doi:10.1017/ S0960428609990217

Anderson S (2002) Identifying Important Plant Areas: a site selection manual for Europe. Plantlife International, Salisbury. www.plantlife.org.uk/publications/identifying_important_plant_areas_a_site_ selection_manual_for_europe. Accessed 19 Sep 2016

Anderson S, Kušík T, Radford E (eds) (2005) Important Plant Areas in central and eastern Europe. Plantlife International, Salisbury. www.plantlife.org.uk/publications/important_plant_areas_in_central_and_ eastern_europe. Accessed 19 Sep 2016

Anderson S, Darbyshire I, Halski B (2016) Important Plant Areas. In: RBG Kew, state of the world's plants report-2016. Royal Botanic Gardens, Kew, p 24-27. https://stateoftheworldsplants.com/report/sotwp_ 2016.pdf. Accessed 19 Sep 2016

Asatryan A, Fayvush G (2013) Important Plant Areas representing the rare and threatened habitat types of Armenia. Nature Rights Protection (NRP), Yerevan

Bachman S, Moat J, Hill AW, de la Torre J, Scott B (2011) Supporting red list threat assessments with GeoCAT: geospatial conservation assessment tool. ZooKeys 150:117-126. doi:10.3897/zookeys.150. 2109

Bachman S, Fernandez EP, Hargreaves S, Nic Lughadha E, Rivers M, Williams E (2016) Extinction risk and threats to plants. In: RBG Kew, state of the world's plants report-2016. Royal Botanic Gardens, Kew, p 58-63

BirdLife International (2014) Important Bird and Biodiversity Areas: a global network for conserving nature and benefitting people. BirdLife International, Cambridge. http://www.birdlife.org/datazone/userfiles/ file/IBAs/pubs/SOWIBAs2014.pdf. Accessed 19 Sep 2016

Bjedov I, Obratov-Petković D, Mišić D, Šiler B, Aleksić JM (2015) Genetic patterns in range-edge populations of Vaccinium species from the central Balkans: implications on conservation prospects and sustainable usage. Silva Fenn. doi:10.14214/sf.1283

Bland LM, Keith DA, Murray NJ, Rodríguez JP (eds) (2015) Guidelines for the application of IUCN Red List of Ecosystems Categories and Criteria. Version 1.0. IUCN, Gland. https://www.iucn.org/sites/dev/ files/content/documents/rle_guidelines_draft_dec_2015.pdf. Accessed 19 Sep 2016

Blasi C, Marignani M, Copiz R, Fipaldini M, Bonacquisti S, Del Vico E, Rosati L, Zavaterro L (2011) Important Plant Areas in Italy: from data to mapping. Biol Conserv 144:220-226

Botanical Society of Britain and Ireland (2016) Axiophytes. http://www.bsbi.org/axiophytes. Accessed 19 Sep 2016

Brooks T, Balmford A, Burgess N, Hansen LA, Moore J, Rahbek C, Williams P, Bennun L, Byaruhanga A, Kasoma P, Njoroge P, Pomeroy D, Wondafrash M (2001) Conservation priorities for birds and biodiversity: Do East African Important Bird Areas represent species diversity in other terrestrial vertebrate groups? Ostrich Suppl 15:3-12

Brown J, Hay-Edie T (2013) COMPACT: engaging local communities in the stewardship of world heritage. UNDP, New York. https://sgp.undp.org/images/Compact_Report_WEB_flat.pdf. Accessed 19 Sep 2016

Brummitt NA, Bachman SP, Griffiths-Lee J, Lutz M, Moat JF, Farjon A, Donaldson JS, Hilton-Taylor C, Meagher TR, Albuquerque S, Aletrari E, Andrews AK, Atchison G, Baloch E, Barlozzini B, Brunazzi A, Carretero J, Celesti M, Chadburn H, Cianfoni E, Cockel C, Coldwell V, Concetti B, Contu S, Crook V, Dyson P, Gardiner L, Ghanim N, Greene H, Groom A, Harker R, Hopkins D, Khela S, LakemanFraser P, Lindon H, Lockwood H, Loftus C, Lombrici D, Lopez-Poveda L, Lyon J, Malcolm-Tompkins P, McGregor K, Moreno L, Murray L, Nazar K, Power E, Quiton Tuijtelaars M, Salter R, Segrott R, Thacker H, Thomas LJ, Tingvoll S, Watkinson G, Wojtaszekova K, Nic Lughadha EM (2015) Green plants in the red: a baseline global assessment for the IUCN Sampled Red List Index for Plants. PLoS ONE 10(8):e0135152. doi:10.1371/journal.pone.0135152

Butchart SHM, Scharlemann JPW, Evans M, Quader S, Arinaitwe J, Bennun LA, Besançon C, Boucher T, Bomhard B, Brooks TM, Burfield IJ, Burgess ND, Clay RP, Crosby MJ, Davidson NC, De Silva N, Devenish C, Dutson GCL, Díaz Fernández DF, Fishpool LDC, Foster M, Hockings M, Hoffmann M, Knox D, Larsen F, Lamoreux JF, Loucks C, May I, Millett J, Parr M, Skolnik B, Upgren A, Woodley S 
(2012) Protecting important sites for biodiversity contributes to meeting global conservation targets. PLoS ONE 7(3):e32529. doi:10.1371/journal.pone.0032529

Byfield A, Atay S, Özhatay N (2010) Important Plant Areas in Turkey: 122 key Turkish botanical sites. WWF Turkey, Istanbul (first published in Turkish in 2005)

Canteiro C, Casteñeda-Álvarez N, Dempewolf H, Eastwood R, Guarino L, Hargreaves S, Hudson A, Khoury CK, Müller JM, Turner R, Ulian T, Willis K (2016) Useful plants. In: RBG Kew, state of the world's plants report-2016. Royal Botanic Gardens, Kew, p 18-23. https://stateoftheworldsplants.com/report/ sotwp_2016.pdf. Accessed 19 Sep 2016

Carrizo SF, Lengyel S, Kapusi F, Szabolcs M, Kasperdius H, Scholz M, Markovic D, Freyhof J, Cid N, Cardoso AC, Darwall W (2014) Freshwater Key Biodiversity Areas across continental Europe: identification, prioritisation and gap-analysis. Biofresh Resour. http://research.freshwaterbiodiversity. eu/index.php/kbas. Accessed 19 Sep 2016

CBD (1992) Convention on Biological Diversity. United Nations. www.cbd.int/doc/legal/cbd-en.pdf. Accessed 19 Sep 2016

CBD (2002) Decision VI/9 Global Strategy for Plant Conservation. In: CBD, report on the sixth meeting of the conference of the parties of the Convention on Biological Diversity, The Hague, 7-19 April 2002, p 139-150. https://www.cbd.int/doc/meetings/cop/cop-06/official/cop-06-20-en.pdf. Accessed 3 Jan 2017

CBD (2012a) Strategic plan for biodiversity 2011-2020, including Aichi Biodiversity Targets. United Nations. www.cbd.int/sp/targets/default.shtml. Accessed 19 Sep 2016

CBD (2012b) The Global Strategy for Plant Conservation 2011-2020. Botanic Gardens Conservation International, Richmond. https://www.bgci.org/files/Plants2020/GSPCbrochure/gspc_english.pdf. Accessed 19 Sep 2016

Corlett RT (2016) Plant diversity in a changing world: status, trends, and conservation needs. Plant Divers 38:10-16. doi:10.1016/j.pld.2016.01.001

Corrigan C, Hay-Edie T (2013) A toolkit to support conservation by indigenous peoples and local communities: building capacity and sharing knowledge for indigenous peoples' and community conserved territories and areas (ICCAs). UNEP-WCMC, Cambridge. http://www.unep.org/dewa/portals/67/pdf/ ICCA_toolkit.pdf. Accessed 19 Sep 2016

Council of Europe (1979) Convention on the Conservation of European Wildlife and Natural Habitats. ETC No. 104. Bern, Switzerland. http://www.coe.int/en/web/conventions/full-list/-/conventions/treaty/104. Accessed 19 Sep 2016

Dimeyeva L, Vesselova P (2015) Identification of Important Plant Areas in Kazakhstan. In Andrianos LA, Sneep JW, Zorbas K (eds) Plants for people, people for plants. 7th Planta Europa conference. Conference proceedings. Horizon Research Publishing, p 52-57. http://www.hrpub.org/download/Planta_ Europa2014.pdf. Accessed 19 Sep 2016

Dines T, Hutchinson N (2008) Developing IPA boundaries in the U.K. Plantlife International, Salisbury. www.plantlife.org.uk/publications/developing_ipa_boundaries_in_the_uk. Accessed 19 Sep 2016

Eken G, Bennun L, Brooks TM, Darwall W, Fishpool LDC, Foster M, Knox D, Langhammer P, Matiku P, Radford E, Salaman P, Sechrest W, Smith ML, Spector S, Tordoff A (2004) Key Biodiversity Areas as site conservation targets. Bioscience 54:1110-1118

Evans S, Marren P, Harper M (2001) Important Fungus Areas: a provisional assessment of the best sites for fungi in the United Kingdom. Plantlife, Salisbury

Fisher JA, Patenaude G, Giri K, Lewis K, Meir P, Pinho P, Rounsevell MDA, Williams M (2014) Understanding the relationships between ecosystem services and poverty alleviation: a conceptual framework. Ecosyst Serv 7:34-45. doi:10.1016/j.ecoser.2013.08.002

Fraser M, Winterbottom S (2010) Identifying and mapping boundaries for Important Plant Areas: Scotland's West Coast Important Plant Area for Atlantic Woodland. Updated version. Plantlife Scotland, Stirling. www. plantlife.org.uk/uploads/documents/West_Coast_IPA_boundary_report_FINAL.pdf. Accessed 19 Sep 2016

Galland P (2015) Convention on the Conservation of European Wildlife and Natural Habitats-35th meeting of the Standing Committee-Strasbourg, 1 December-4 December 2015-hydro power development within the territory of Mavrovo National Park ("The former Yugoslav Republic of Macedonia")—on-the-spot appraisal (anglais seulement) T-PVS/Files (2015)36E. https://wcd.coe.int/ com.instranet.InstraServlet?command=com.instranet.CmdBlobGet\&InstranetImage=2890492\&SecMode $=$ $1 \&$ DocId=2322722\&Usage=2. Accessed 21 Dec 2016

Gaston KJ, Fuller RA (2008) The sizes of species' geographic ranges. J Appl Ecol 46:1-9. doi:10.1111/j. 1365-2664.2008.01596.x

Gerlach J (2008) Setting conservation priorities - a Key Biodiversity Area analysis for the Seychelles Islands. Open Conserv Biol J 2:44-53. doi:10.2174/1874839200802010044

Grimmett RFA, Jones TA (1989) Important Bird Areas in Europe. International Council for Bird Preservation, Cambridge 
Hamilton AC, Radford EA (2007) Identification and conservation of Important Plant Areas for medicinal plants in the Himalaya. Plantlife International, Salisbury. www.plantlife.org.uk/publications/ identification_and_conservation_of_important_plant_areas_for_medicinal. Accessed 19 Sep 2016

Hampe A, Petit RJ (2005) Conserving biodiversity under climate change: the rear edge matters. Ecol Lett 8:461-467. doi:10.1111/j.1461-0248.2005.00739.x

Harrison PA, Berry PM, Simpson G, Haslett JR, Blicharska M, Bucur M, Dunford R, Egoh B, GarciaLlorente M, Geamănă N, Geertsema W, Lommelen E, Meiresonne L, Turkelboom F (2014) Linkages between biodiversity attributes and ecosystem services: a systematic review. Ecosyst Serv 9:191-203. doi:10.1016/j.ecoser.2014.05.006

Heath MF, Evans IE (eds) (2000). Important Bird Areas in Europe; priority sites for conservation, 2 volumes. BirdLife Conservation Series No. 8. BirdLife International, Cambridge

Heino J (2010) Are indicator groups and cross-taxon congruence useful for predicting biodiversity in aquatic ecosystems? Ecol Indic 10:112-117. doi:10.1016/j.ecolind.2009.04.013

Heywood V, Casas A, Ford-Lloyd B, Kell S, Maxted N (2007) Conservation and sustainable use of crop wild relatives. Agric Ecosyst Environ 121:245-255. doi:10.1016/j.agee.2006.12.014

Hofmeyr W (ed) (2004) Proceedings of the Important Plant Areas workshop. Unpublished report. National Botanical Research Institute, Pretoria

Holland RA, Darwall WRT, Smith KG (2012) Conservation priorities for freshwater biodiversity: the Key Biodiversity Area approach refined and tested for continental Africa. Biol Conserv 148:167-179. doi:10.1016/j.biocon.2012.01.016

IUCN (2012) IUCN Red List Categories and Criteria. Version 3.1, 2nd edn. IUCN Species Survival Commission, Gland. http://www.iucnredlist.org/technical-documents/categories-and-criteria/2001categories-criteria. Accessed 19 Sep 2016

IUCN (2014) Conserving wild plants and habitats for people across the Mediterranean. https://www.iucn. org/content/conserving-wild-plants-and-habitats-people-across-mediterranean. Accessed 19 Sep 2016

IUCN (2016) A global standard for the identification of Key Biodiversity Areas, version 1.0, 1st edn. IUCN, Gland. https://portals.iucn.org/library/sites/library/files/documents/Rep-2016-005.pdf. Accessed 19 Sep 2016

IUCN Sampled Red List Index for Plants (2012) Plants under pressure-a global assessment. Royal Botanic Gardens, Kew. http://www.kew.org/sites/default/files/kppcont_027709.pdf. Accessed 19 Sep 2016

IUCN Standards and Petitions Subcommittee (2014) Guidelines for using the IUCN Red List Categories and Criteria. Version 11. Prepared by the Standards and Petitions Subcommittee. http://www.iucnredlist. org/documents/RedListGuidelines.pdf. Accessed: 19 Sep 2016

Jones M (2008) Distribution and conservation of Montserrat's endemic flora. Unpublished MSc Thesis, Imperial College, London

Joppa LN, Butchart SH, Hoffmann M, Bachman SP, Akçakaya HR, Moat JF, Böhm M, Holland RA, Newton A, Polidoro B, Hughes A (2016) Impact of alternative metrics on estimates of extent of occurrence for extinction risk assessment. Conserv Biol 30:362-370. doi:10.1111/cobi.12591

Kasecker TP, Silva JMC, Rapini A, Ramos-Neto MB, Andrade MJG, Giulietti AM, Queiroz LP (2009) Áreas-chave para espécies raras de fanerógamas. In: Giulietti AM et al (eds) Plantas raras do Brasil. Conservação Internacional, Belo Horizonte, p 433-471

Kati V, Devillers P, Dufréne M, Legakis A, Vokou D, Lebrun P (2004) Testing the value of six taxonomic groups as biodiversity indicators at a local scale. Conserv Biol 18:667-675. doi:10.1111/j.1523-1739. 2004.00465.x

Langhammer PF, Bakarr MI, Bennun LA, Brooks TM, Clay RP, Darwall W, De Silva N, Edgar GJ, Eken G, Fishpool LDC, da Fonseca GAB, Foster MN, Knox DH, Matiku P, Radford EA, Rodrigues ASL, Salaman P, Sechrest W, Tordoff AW (2007) Identification and gap analysis of Key Biodiversity Areas: targets for comprehensive protected area systems. IUCN, Gland

Leppig G, White JW (2006) Conservation of peripheral plant populations in California. Madroño 53:264-274

Linsky J (2014) Distribution and conservation of threatened plant species on Anegada, British Virgin Islands. Unpublished MSc Thesis, Imperial College, London

Llewellyn OA, Hall M, Miller AG, Al-Abbasi TM, Al-Wetaid AH, Al-Harbi RJ, Al-Shammari KF (2011) Important Plant Areas in the Arabian Peninsula: 4. Jabal Aja'. Edinb J Bot 67:37-56. doi:10.1017/ S0960428611000059

Lockton A (2005) From the co-ordinator: new word competition. BSBI News 97:5

Lund MP, Rahbek C (2002) Cross-taxon congruence in complementarity and conservation of temperate biodiversity. Anim Conserv 5:163-171. doi:10.1017/S1367943002002226Manhaes 
Manhaes AP, Mazzochini GG, Oliveira AT, Ganade G, Carvalho AR (2016) Spatial associations of ecosystem services and biodiversity as a baseline for systematic conservation planning. Divers Distrib 22:932-943

Margules CR, Pressey RL (2000) Systematic conservation planning. Nature 405:243-253

Marignani M, Blasi C (2012) Looking for important plant areas: selection based on criteria, complementarity, or both? Biodivers Conserv 21:1853-1864. doi:10.1007/s10531-012-0283-5

Mátyás C, Fady B, Vendramin GG (2009) Forests at the limit: evolutionary-genetic consequences of environmental changes at the receding (xeric) edge of distribution. Report from a researcher workshop. Acta Silv Lignaria Hung 5:201-204

Maxted N, Kell S, Ford-Lloyd B, Dulloo E, Toledo Á (2012) Toward the systematic conservation of global crop wild relative diversity. Crop Sci 52:774-785. doi:10.2135/cropsci2011.08.0415

Melovski LJ, Matevski V, Kostadinovski M, Karadelev M, Angelova N, Radford EA (2010) Important Plant Areas in the Republic of Macedonia, vol 9. Special issue of Macedonian Ecological Society, Skopje (in Macedonian)

Melovski L, Velevski M, Matevski V, Avukatov V, Sarov A (2012) Using Important Plant Areas and Important Bird Areas to identify Key Biodiversity Areas in the Republic of Macedonia. J Threat Taxa 4:2766-2778

ÖBANET (2015) IPANET_volunteer network for the Important Plant Areas in Turkey. http://obanettr.org/ default.asp?baslik=about_us\&page=1\&a=97\&b=1\&c=79\#. Accessed 14 Dec 2016

Özhatay N (2006) Important Plant Areas along BTC Pipeline in Turkey. BTC Şirketi, İstanbul

Paese A, Paglia A, Pinto LP, Foster MN, Fonseca M, Sposito R (2010) Fine-scale sites of global conservation importance in the Atlantic Forest of Brazil. Biodivers Conserv 19:3445-3458. doi:10.1007/ s10531-010-9906-X

Peh KS-H, Balmford A, Bradbury RB, Brown C, Butchart SHM, Hughes FMR, Stattersfield A, Thomas DHL, Walpole M, Bayliss J, Gowing D, Jones JPG, Lewis SL, Mulligan M, Pandeya B, Stratford C, Thompson JR, Turner K, Vira B, Willcock S, Birch JC (2013) TESSA: a toolkit for rapid assessment of ecosystem services at sites of biodiversity conservation importance. Ecosyst Serv 5:51-57. doi:10. 1016/j.ecoser.2013.06.003

Perini C, Leonardi P, Pecoraro L, Salerni E (2011) The Important Plant Areas program from a mycological point of view: the regional experience in an European context. Fitosociologia 48(2 Suppl. 1):155-161

Pimm SL, Joppa LN (2015) How many plant species are there, where are they, and at what rate are they going extinct? Ann Mo Bot Gard 100:170-176. doi:10.3417/2012018

Plantlife (2010a) IPA online database. www.plantlife.org.uk/international/wild_plants/IPA/ipa_online_ database. Accessed 19 Sep 2016

Plantlife (2010b) Important Plant Areas around the world: Target 5 of the CBD Global Strategy for Plant Conservation. Plantlife International, Salisbury. www.plantlife.org.uk/publications/important_plant_ areas_around_the_world. Accessed 19 Sep 2016

Plantlife (2013) Natural networks, people, plants, places. Plantlife International, Salisbury. http://www. plantlife.org.uk/uploads/documents/Natural_networks_spreads.pdf. Accessed 19 Sep 2016

Plantlife International (2004) Identifying and protecting the world's most Important Plant Areas. Plantlife International, Salisbury. www.plantlife.org.uk/publications/identifying_and_protecting_the_worlds_ most_important_plant_areas. Accessed 19 Sep 2016

Plantlife International (2010) Important Plant Areas in Europe (2002-2010): priority sites for people and plants. Plantlife International, Salisbury. www.plantlife.org.uk/publications/important_plant_areas_in_ europe_2002-2010_priority_sites_for_plants_an. Accessed 19 Sep 2016

Radford EA, Odé B (eds) (2009) Conserving Important Plant Areas: investing in the Green Gold of South East Europe. Plantlife International, Salisbury. http://www.plantlife.org.uk/uploads/documents/IPAa_ SEE_report_web.pdf. Accessed 19 Sep 2016

Radford EA, Catullo G, de Montmollin B (eds) (2011) Important Plant Areas of the south and east Mediterranean region: priority sites for conservation. IUCN, Gland. www.plantlife.org.uk/publications/ IPA-SEMed. Accessed 19 Sep 2016

Ravera S, Nimis PL, Brunialti G, Frati L, Isocrono D, Martellos S, Munzi S, Nascimbene J, Potenza G, Tretiach M (2011) The role of lichens in selecting Important Plant Areas in Italy. Fitosociologia 48(2, Suppl. 1):145-153

Rehm EM, Olivas P, Stroud J, Feeley KJ (2015) Losing your edge: climate change and the conservation value of range-edge populations. Ecol Evol 5:4315-4326. doi:10.1002/ece3.1645

RBG Kew (2016) Tropical Important Plant Areas. http://www.science.kew.org/strategic-output/tropicalimportant-plant-areas. Accessed 19 Sep 2016

Ricketts TH, Dinerstein E, Boucher T, Brooks TM, Butchart SHM, Hoffmann M, Lamoreux JF, Morrison J, Parr M, Pilgrim JD, Rodrigues ASL, Sechrest W, Wallace GE, Berlin K, Bielby J, Burgess ND, Church 
DR, Cox N, Knox D, Loucks C, Luck GW, Master LL, Moore R, Naidoo R, Ridgely R, Schatz GE, Shire G, Strand H, Wettengel W, Wikramanayake E (2005) Pinpointing and preventing imminent extinctions. Proc Natl Acad Sci USA 102:18497-18501. doi:10.1073/pnas.0509060102

Sabatini FM, Burrascano S, Azzella MM, Barbati A, De Paulis S, Di Santo D, Facioni L, Giuliarelli D, Lombardi F, Maggi O, Mattioli W, Parisi F, Persiani A, Ravera S, Blasi C (2016) One taxon does not fit all: herb-layer diversity and stand structural complexity are weak predictors of biodiversity in Fagus sylvatica forests. Ecol Indic 69:126-137. doi:10.1016/j.ecolind.2016.04.012

Saenz S, Walschburger T, González JC, León J, McKenney B, Kiesecker J (2013) Development by design in Colombia: making mitigation decisions consistent with conservation outcomes. PLoS ONE 8(12):e81831. doi:10.1371/journal.pone.0081831

SANBI (2015) Red List of South African plants. Version 2015.1. http://redlist.sanbi.org/. Accessed 15 Dec 2016

Sandifer PA, Sutton-Grier AE, Ward BP (2015) Exploring connections among nature, biodiversity, ecosystem services, and human health and well-being: opportunities to enhance health and biodiversity conservation. Ecosyst Serv 12:1-15. doi:10.1016/j.ecoser.2014.12.007

Sârbu A, Sârbu I, Oprea A, Negrean G, Cristea V, Gheorghe C, Cristurean I, Popescu G, Oroian S, Tănase C, Bartók K, Gafta D, Anastasiu P, Crişan F, Costache I, Goia I, Maruşca T, Oţel V, Sămărghiţan M, Henţea S, Pascale G, Răduţoiu D, Baz A, Boruz V, Puşcaş M, Hiriţiu M, Stan I, Frink J (2007) Arii speciale pentru protecţia şi conservarea plantelor în România. In: Important Plant Areas (IPA-s) in Romania. Victor B Victor, Bucureşti

Sharrock S (2012) Global Strategy for Plant Conservation. A guide to the GSPC: all the targets, objectives and facts. Botanic Gardens Conservation International, Richmond. http://www.plants2020.net/files/ Plants2020/popular_guide/englishguide.pdf. Accessed 19 Sep 2016

Sharrock S, Oldfield S, Wilson O (2014) Plant Conservation Report 2014: a review of progress in implementation of the Global Strategy for Plant Conservation 2011-2020. Secretariat of the Convention on Biological Diversity, Montréal, and Botanic Gardens Conservation International, Richmond. Technical Series No. 81. https://www.cbd.int/doc/publications/cbd-ts-81-en.pdf. Accessed 19 Sep 2016

Smith TJ (ed) (2005). Important Plant Areas in southern Africa. In: Combined proceedings of workshops held in Mozambique, Namibia and South Africa. Southern African Botanical Diversity Network Report Series No. 39. SABONET, Pretoria

Smith TJ, Smith GF (2004) Selecting Important Plant Areas in southern Africa. S Afr J Sci 100:434-435

Smith RJ, Goodman PS, Matthews WS (2006) Systematic conservation planning: a review of perceived limitations and an illustration of the benefits, using a case study from Maputaland, South Africa. Oryx 40(4):400-410. doi:10.1017/S0030605306001232

Stewart NF (2004) Important Stonewort Areas. An assessment of the best areas for stoneworts in the United Kingdom (summary). Plantlife International, Salisbury. www.plantlife.org.uk/publications/important_ stonewort_areas_-_an_assessment_of_the_best_sites_for_stonew. Accessed 19 Sep 2016

Sunderland TCH (2011) Food security: Why is biodiversity important? Int For Rev 13:265-274. doi:10. $1505 / 146554811798293908$

Union European (1992) Council Directive 92/43/EEC of 21 May 1992 on the conservation of natural habitats and of wild fauna and flora (the Habitats Directive). Off J Eur Communities L 206:7-50

United Nations (2015) Transforming our world: the 2030 agenda for sustainable development. United Nations General Assembly resolution A/RES/70/1. https://sustainabledevelopment.un.org/content/ documents/21252030\%20Agenda\%20for\%20Sustainable\%20Development\%20web.pdf. Accessed 19 Sep 2016

Upson R (2012) Important Plant Areas of the Falkland Islands. Falklands Conservation. www.kew.org/sites/ default/files/Important\%20Plant\%20Areas\%20of\%20the\%20Falkland\%20Islands.pdf. Accessed 19 Sep 2016

Upson R, Williams JJ, Wilkinson T, Clubbe CP, Maclean IMD, McAdam JH, Moat JF (2016) Potential impacts of climate change on native plant distributions in the Falkland Islands. PLoS ONE 11(11):e0167026. doi:10.1371/journal.pone.0167026

van Swaay CAM, Warren MS (2006) Prime butterfly areas in Europe: an initial selection of priority sites for conservation. J Insect Conserv 10:5-11. doi:10.1007/s10841-005-7548-1

von Staden L, Lotter M (2015) Target 5: important areas for plant diversity identified and incorporated into conservation processes. In: Raimondo D (ed) South Africa's strategy for plant conservation. South African National Biodiversity Institute and the Botanical Society of South Africa, Pretoria, pp 26-29

Walter KS, Gillett, HJ (1997) 1997 IUCN Red List of Threatened Plants. Compiled by the World Conservation Monitoring Centre. IUCN: The World Conservation Union, Gland

Williams S (2009) The identification and conservation of Important Plant Areas: a case study from the Turks and Caicos Islands. Unpublished MSc Thesis, Imperial College, London 
Xu J, Lebel L, Sturgeon J (2009) Functional links between biodiversity, livelihoods, and culture in a Hani Swidden Landscape in southwest China. Ecol Soc 14(2):art. 20. http://www.ecologyandsociety.org/ vol14/iss2/art20/. Accessed 19 Sep 2016 